\title{
Las cuevas de Giribaile: nuevas aportaciones para el estudio del poblamiento eremítico en Andalucía Oriental
}

\author{
Luis María Gutiérrez Soler* \\ Carmen Rueda Galán* \\ Mercedes Beatriz Luna*** \\ María José Díaz García***
}

\begin{abstract}
RESUMEN
Este artículo recoge los trabajos realizados en el año 200 I en la Zona Arqueológica de Giribaile (Vilches, Jaén) centrados en la documentación de un conjunto eremítico, de carácter rupestre, así como una necrópolis asociada a este poblamiento.
\end{abstract}

PALABRAS CLAVE: rupestre, eremítico, Giribaile.

\section{INTRODUCCIÓN}

"Llámase hoy Cuevas de Mari-Algar (Ma-Al-garb; esto es, Fuente del Ocaso) la que aparece en la lámina. Otras cuevas hay a la izquierda del que lo mira y fueron defensas, según las escaleras interiores y troneras, abiertas a pico, que observa allí el curioso viajero. En la meseta de sitio tan excelente, se alzó, a mi parecer, sin duda alguna, la Giri de Plutarco"

(GÓNGORA, 1916: 7-8).

Con estas palabras Manuel de Góngora describió por primera vez, en 1860, las que hoy conocemos como Cuevas de Giribaile. El objetivo de este artículo es presentar los trabajos de limpieza y documentación arqueológica de

\begin{abstract}
This paper show the results of the archaeological intervention carry out at the archaeological area of Giribaile (Vilches, Jaén). The archaeological works were focused on the heremitic cave group and the cementery next to it.
\end{abstract}

KEY WORDS: cave, heremitic, Giribaile.

una serie de complejos rupestres encuadrados, probablemente, en época altomedieval (GUTIÉRREZ et alii, 2004). Este estudio pretende contribuir a completar y definir la secuencia histórico-arqueológica de Giribaile y, a la vez, poder valorar la problemática que plantea el análisis e interpretación de unos eremitorios mal conocidos en esta zona de Andalucía.

Por otro lado, supone la continuidad de una línea de investigación abierta en el sitio desde que en 1992 se llevara a cabo la prospección de superficie en los terrenos de la presa de Giribaile, que desembocó en la realización de la tesis doctoral titulada El poblamiento ibérico en

\footnotetext{
* Universidad de Jaén. Centro Andaluz de Arqueología Ibérica.
} **Arqueólogas profesionales. 
el curso medio del río Guadalimar (GUTIÉRREZ, 1998) y en la reciente publicación El oppidum de Giribaile (GUTIÉRREZ, 2002). Esta monografía recoge los informes inéditos de las campañas de excavación dirigidas en 1968-1969 por el geólogo francés Georges Servajean, apoyado por el Grupo Arqueológico Carolinense. La actividad arqueológica realizada en la zona central del poblado permitió obtener una documentación muy interesante para la comprensión del proceso histórico en este oppidum de época ibérica (SERVAJEAN et alii, 1986).

Esta actividad de investigación se completó, desde un punto de vista administrativo, con la iniciativa de la Delegación Provincial de la Consejería de Cultura de la Junta de Andalucía de llevar a cabo la elaboración de la documentación necesaria para la incoación del Expediente de Inscripción de Giribaile como Zona Arqueológica en el catálogo General de Patrimonio Histórico de Andalucía, además de realizar un campo de trabajo entre cuyos objetivos estaba la recuperación y conservación de determinadas estructuras que se encontraban afectadas por procesos de deterioro (CHOCLÁN, 1986).

Actualmente nos encontramos trabajando en el proyecto de creación de un centro de interpretación sobre Giribaile, con la intención de fomentar la continuidad de la investigación y definir fórmulas de musealización y difusión de este sitio arqueológico.

\section{DEFINICIÓN ARQUEOLÓGICA DE GIRIBAILE}

Giribaile se localiza en el término municipal de Vilches (Jaén), más concretamente en la confluencia de los ríos Guadalimar y Guadalén, muy cercano a la aldea de Miralrío. Ocupa una meseta que destaca con relación al entorno más próximo y domina una amplia vega, lo que, sin duda, ha marcado el devenir histórico de esta zona, con una secuencia crono-cultural que abarca varios períodos.

La primera ocupación, con carácter más o menos permanente, corresponde, grosso modo, a los siglos VIII-VII ane, un momento aún poco caracterizado en el yacimiento, por lo que en la actualidad es muy complicado poder hablar de la entidad de este sitio durante la Prehistoria Reciente (NOCETE, CRESPO, ZAFRA, 1986).

La siguiente fase, tras un hiatus, corresponde a inicios del siglo IV ane, momento en el que se funda el oppidum de Giribaile, que llegó a alcanzar unas 15 has de meseta fortificada, configurándose como una de las grandes ciudades del Alto Guadalquivir (RUIZ RODRÍGUEZ, MOLINOS, 1993). Por otra parte, este núcleo formaría parte, con una vocación estratégica importante, de la ordenación del pago de Cástulo, ciudad que se convirtió en un centro destacado, debido, fundamentalmente, al control que ejerció sobre la cuenca de los ríos GuadalénMontizón y sobre un amplio territorio minero. Esta situación conllevó la adopción de nuevas fórmulas de control político y social. Para ello, desde el punto de vista ideológico, se instalan dos santuarios en la cabecera de este territorio, Collado de los Jardines, en Santa Elena, y la Cueva de la Lobera, en Castellar, pero, además, desde el punto de vista político, se funda el oppidum de Giribaile como núcleo secundario y lugar estratégico y de control en la confluencia de los valles del Guadalimar y Guadalén (RUIZ RODRÍGUEZ et alii, 200 I).

Giribaile representa un buen ejemplo del modo en el que se llevó a cabo el proceso de romanización después de finalizar la Segunda Guerra Púnica. La ocupación de Giribaile continúa, aparentemente, hasta finales del siglo II inicios del I ane, momento en el que se documenta una destrucción violenta, hecho que, muy probablemente, corresponde a una acción militar de castigo encabezada por el cónsul Tito Didio, que tenía a su cargo un destacamento que hibernaba en la vecina ciudad de Cástulo.

Tras la destrucción se produce un abandono de la meseta y una disgregación de población que empieza a establecerse en el valle, constituyéndose La Monaria en el núcleo más importante. Para momentos posteriores de época romana, en la meseta sólo se documentan algunos fragmentos de terra sigillata hispánica, fruto de una ocupación puntual de tipo rural de época flavia. 
La siguiente fase corresponde a un momento indeterminado, altomedieval, en el que se documenta un núcleo eremítico. Estas evidencias deben ponerse con relación a la presencia en el valle de sitios de características similares como las Cuevas de la Veguilla, en Canena (CASAS, 2000), o el oratorio de Valdecanales, en Rus (VAÑÓ, 1970; HAUSCHILD, SCHLUNK, 1970; NAVASCUÉS, 1970), comenzando a definir en el territorio un poblamiento rupestre de cierta entidad, que aún no ha sido estudiado sobre la base de criterios de investigación comunes cronológicos y funcionales, y que viene a sumarse a otras manifestaciones de utilización de cuevas en Andalucía Oriental, como el grupo de "covarrones" definido en torno a Guadix (BERTRAND, 1986; ASENJO, 1990) O las denominadas "ventanas", en la provincia de Almería (BARRIONUEVO, 1986), aunque la mayor parte de los casos estudiados responden a contextos históricos más tardíos.

En Giribaile el poblamiento rupestre podría relacionarse con una ocupación de época tardorromana y/o visigoda detectada en el llano y en las laderas de la meseta de Giribaile, ocupación que continúa hasta época emiral con la configuración de un hișn, fortificación que se reutiliza en época almohade y que se abandona hacia los siglos XIV-XV (CASTILLO, 1997).

La última fase de hábitat, de mediados del siglo $\mathrm{XX}$, corresponde a la instalación en la vertiente sur de la meseta de un cortijo dedicado a la explotación del olivar, dando lugar a una ocupación estacional, que es interesante no sólo por la existencia actual de vestigios materiales de la misma, sino, fundamentalmente, por la reutilización y reestructuración que realizaron de los complejos rupestres, procesos que han podido ser leídos en el desarrollo de nuestros trabajos de documentación en las Cuevas de Giribaile.

\section{DESCRIPCIÓN FORMAL DEL CONJUNTO RUPESTRE}

Un estudio de las características del que se ha llevado a cabo presenta una problemática particular con relación a la continuidad y a la diversidad de usos a los que se han dedicado los diferentes espacios que se definen en el interior de las Cuevas de Giribaile, alteraciones o modificaciones que, sin duda, han influido en la configuración actual de las mismas. Por todo ello debemos resaltar la relevancia de una correcta lectura temporal que intenta definir, en un mismo espacio, huellas resultantes del devenir de muchos siglos de historia.

Todos los complejos rupestres documentados, un total de cuatro, se ubican en el farallón localizado en la vertiente sur de la meseta de Giribaile. Directamente relacionados con estas estructuras están los hallazgos de tumbas situadas junto al cortijo de Casas Altas. A este hábitat rupestre habría que añadir otras dos cavidades aisladas del conjunto, a las que tradicionalmente se ha denominado Piedra Horadada y Piedra Hueca o bien Piedra Hueca Grande y Pequeña, localizadas ambas en la vertiente norte de esta misma meseta. Habría que señalar que la tradición oral habla de otro grupo de cuevas muy similares a los conjuntos rupestres 3 y 4 , ubicadas en el extremo oeste del farallón, comunicaciones que no han podido ser corroboradas debido a la imposibilidad física de acceso a esta zona por el desmoronamiento de parte del farallón.

Para una mejor comprensión, tanto de conjunto como de los elementos individualizados, hemos creído oportuno realizar una descripción detallada de cada una de las unidades objeto de investigación para, posteriormente, hacer un análisis de conjunto, contextualizando los resultados obtenidos en el territorio.

\section{EI complejo ruprestre I}

Ocupa una posición central dentro del conjunto. Denominada como "Cuevas de la Mujer", en referencia a un relieve tallado en una de las naves, esta construcción ha sido identificada, tradicionalmente, con un lugar de culto. La situación de este complejo antes de la intervención era de total abandono, ya que había sido reutilizado como establo, por lo que la primera actuación consistió en la limpieza del mismo. 
Se trata de un edificio excavado completamente en la roca, aprovechando una cavidad natural, tal y como puede deducirse de una de sus naves (la número 4), que quedó finalmente inacabada. La planta es de cinco naves, numeradas de izquierda a derecha siguiendo la orientación sur-norte, y se remata con un espacio continuo, a modo de cabecera, que se comunica directamente con tres de las estancias, las dos de los extremos y la central. Para la construcción de este edificio se utilizó un módulo cuadrangular en las naves I, 2, 4 y 5, mientras que, por el contrario, las dos naves restantes, la 3 y la 6, parecen regirse por un sistema distinto y se constituyen como el eje axial y, probablemente, el más importante del edificio.

Una característica fundamental de su planta es la total simetría, simetría que se expresa igualmente en los accesos, que originariamente eran tres, los correspondientes a las naves impares, aunque en la actualidad existe otra entrada, la de la nave 2, que se abrió con posterioridad, muy probablemente en "I935", ya que esta fecha queda marcada en la pared sur del pasillo, hipótesis que es corroborada por comunicaciones personales de gente del lugar. Las entradas responden todas al mismo esquema, corredor, al que se accede por medio de escalones excavados en la roca. En todas ellas existen huellas de cerramiento. Este ideal de simetría se expresa, incluso, en los pequeños detalles y elementos de su arquitectura como rebajes, vanos u hornacinas.

Las cubiertas de los espacios longitudinales (las denominadas naves 3 y 6), corresponden al tipo de bóveda de cañón rebajada, mientras que en el resto de estancias, que responden a un módulo cuadrangular (naves I, 2, 4 y 5) presentan cubiertas casi planas. Por lo que respecta a los ingresos desde el exterior, estos se practican a través de vanos que se cierran con arcos de medio punto, dando acceso a un estrecho pasillo de casi $2 \mathrm{~m}$ de longitud y no más de I $\mathrm{m}$ de ancho, mientras que los pasos interiores se muestran, en cuanto a dimensiones, mucho más irregulares.

Las paredes no presentan ningún tipo de revoco y una vez concluidos los trabajos de lim- pieza es posible apreciar las huellas dejadas por los instrumentos empleados en la labra de la roca. El único tratamiento de decoración consiste en la utilización de pintura roja generalizada en el techo, además de conservarse en el zócalo de la nave central. Esto, junto al encalado de las paredes, muestra la reutilización de estas estancias como lugar de hábitat y, posteriormente, como establo. De esta misma época aún se conservaban restos de pavimento consistente en un piso de tierra compactada superpuesto a un relleno de tierra y piedras que permitía salvar los desniveles de la roca.

A continuación presentamos una descripción detallada de cada una de las unidades espaciales que la conforman, para facilitar la comprensión estructural y realizar una lectura más favorable de las distintas fases identificables.

La primera estancia, definida como nave I, simétrica a la 5 , se trata de una sala rectangular con unas dimensiones de 3'40 × 4'80 m y una altura de $2 \mathrm{~m}$, a la que se accede mediante un pasillo de $2 \times 0$ ' $60 \mathrm{~m}$. Se comunica con dos estancias, de una parte con la nave 2, por medio de un corredor de l'50 × l'50 m, y de la otra, con la nave 6 , a través de un pasillo de I'30 × l'70 m. En la zona central de la estancia y en el lugar de paso entre las naves 1 y 6 se documentó parte de un pavimento de tierra apisonada, de época reciente, bajo el cual se localizaron dos rebajes en la roca, de tipo circular, uno de los cuales tiene su correspondiente en la cubierta de la misma, sin que se haya podido obtener una lectura en cuanto a su funcionalidad.

En la zona central de la pared sur, a I m de suelo aproximadamente, se abre una hornacina rectangular con terminación curva, simétrica a la documentada en la pared norte de la nave 5. Este elemento funcional reafirma la concepción simétrica del edificio.

En esta nave se documentaron numerosos rebajes en la roca, de distinta forma y tamaño, que pueden responder a funcionalidades diversas. De un lado, en los ángulos sureste y noreste se observan dos rebajes circulares, muy similares a otros presentes en el resto de las naves, 
que parecen corresponder a agujeros empleados para la sujeción de recipientes de almacenaje, pudiendo relacionarse con la etapa de utilización de la cueva como hábitat. Existen otro tipo de rebajes alineados en la pared norte y bajo el pavimento, así como uno de forma rectangular documentado junto al acceso a esta nave, de los que no se ha podido obtener una interpretación válida sobre su funcionalidad.

La siguiente estancia, la nave 2, simétrica a la nave 4, presenta, igualmente, forma rectangular con unas dimensiones de 5'50 × 3'20 m y una altura máxima de 2'30 m. Se comunica con la nave I y con la 3, pudiendo acceder a esta última a través de un pasillo de I'30 × I m. Fue, precisamente, en este corredor, bajo el pavimento, donde se documentaron tres rebajes excavados en la roca, dos juntos de forma circular y uno cuadrangular que, funcionalmente, parecen corresponder a soportes para encajar recipientes de almacenaje.

Un relleno de tierra y piedras, utilizado como nivelación de una gran irregularidad del suelo natural de la roca, recubría la mayor parte de la estancia, extendiéndose hasta enlazar con la nave I. Bajo el relleno también se localizaron algunos rebajes circulares, concretamente tres, pegados a las paredes este, norte y sur. Resulta muy complicado obtener la funcionalidad de estos orificios a partir de una lectura de la estructura formal del edificio. En total son nueve los rebajes documentados en esta estancia, casi todos circulares, ya que a los citados por el momento habría que añadir otros dos en los ángulos sureste y suroeste y otro más, muy cercano a la puerta de entrada.

Una peculiaridad de esta estancia es la presencia, en su pared oeste, de una talla en altorrelieve de un desnudo femenino y de un busto de mujer, ambas de similar factura, muy deterioradas por la aplicación de varias capas de cal. La primera figura se trata de una talla en la roca que representa un desnudo completo, en un escorzo forzado que intenta representar movimiento. Esta imagen se rige por fórmulas de proporción y volumen y se manifiesta de forma naturalista. Queda encuadrada en un marco, igualmente rebajado en la roca. La segunda figura, también en altorrelieve, se trata de un busto femenino de perfil, esquemático y hierático, encuadrado también en un marco rectangular que se cierra, en su parte inferior, en una forma curva. Es en esta parte inferior donde el autor anónimo dejó plasmadas las iniciales 'PA'.

La nave 3 constituye el eje axial o de simetría del edificio y, junto a la nave 6 , forma un espacio continuo que se aparta del módulo descrito para las naves I, 2, 4 y 5. Esta estancia, mucho más alargada y estrecha, conecta con el corredor que se conforma como una cabecera rectilínea, reproduciendo el esquema de una "T". En el lugar exacto que marca la unión perfecta entre ambas naves, en altura, bajo varias capas de cal, se documentó una cruz incisa, que responde al modelo de cruz latina apoyada sobre círculo que, iconográficamente, puede relacionarse con un tipo de representación característico de las comunidades cristianas. Debajo de la cruz se localizan tres orificios circulares alineados, todos del mismo diámetro, que recuerdan los documentados en la sala I de la Cueva A de Valdecanales (VAÑó, 1970) y que, aparentemente, pudieron servir para encajar algún elemento mueble que con el paso del tiempo se ha perdido. Además, en el lugar de encuentro de las naves 3 y 6 el nivel de base ha sido rebajado por debajo de la cota del resto de las estancias, conformando un espacio privilegiado y destacado por su mayor altura, con un total de 2'70 m.

La nave 3, además de confluir con la estancia número 6 , también queda comunicada con las naves 2 y 4 y posee un acceso directo desde el exterior que responde al mismo esquema de entrada con corredor que ya comentamos anteriormente.

En cuanto a los rebajes excavados en la roca de esta estancia, a excepción del que presenta forma rectangular, apoyado en la pared norte, junto al acceso que comunica con la nave 4, éstos básicamente se localizan en una zona muy próxima a la nave 6 y en ningún caso ha sido posible obtener datos sobre la funcionalidad concreta de los mismos. Por otra parte, se debe hacer mención de la existencia de una línea 
incisa en la roca de las pareces norte y sur, a I m aproximadamente del suelo, asociadas a mortajas cuadrangulares de pequeño tamaño que, aparentemente, debería interpretarse como una huella en negativo de algún tipo de anclaje que permitiera fijar un elemento mueble.

La nave 4, simétrica a la 2, corresponde a una estancia que reaprovecha una gruta natural que fue inicialmente regularizada, pero que quedó como obra inacabada, por lo que sus dimensiones, comparadas con el módulo empleado en las naves I, 2 y 5 son algo menores. En esta sala se han documentado dos rebajes de forma circular excavados en la roca, uno en la pared norte, sin funcionalidad establecida, y una peculiar zona de paso, también excavada que, a modo de pasillo, comunica esta estancia con las naves 3 y 5 .

Es en la nave 5 , simétrica a la I, donde mejor se ha documentado su reutilización como lugar de hábitat contemporáneo, tal y como muestra la presencia de una chimenea en el ángulo noreste de la habitación, al igual que un banco corrido excavado en la roca, que recorre parte de la pared sur y la totalidad del frente oeste. Esta sala se comunica directamente con las naves 4 y 6 , con esta última mediante un acceso simétrico al documentado en la nave I. Este concepto de simetría también está presente en la entrada desde el exterior, al igual que en la hornacina rectangular ubicada en la pared norte, que se corresponde a la presente en la nave I.

Por último, hay que señalar que también se ha documentado en el centro de la sala un rebaje de forma rectangular, muy parecido a los hallados en las naves I y 3 , aunque no se puede precisar su función, y entalles en las paredes que comunican esta nave 5 con la 6, para disponer tablas horizontales apoyadas en los muros, como si de estantes o anaqueles se tratase.

La nave 6 se corresponde con el brazo superior de la "T". Su forma es alargada y continua y recorre, a modo de cabecera, la longitud total del edificio (22'5 m), conectando con las naves I, 3 y 5 y se rige por una modulación distinta.
En este espacio pueden distinguirse tres ambientes diferenciados, separados por tres escalones localizados en la zona sur, a la altura de la posición que ocupa la nave 2, y otros dos, colocados de forma simétrica, en la zona norte, dispuestos a la altura de la nave 4. El nivel de la base del espacio central, como ya se ha señalado al tratar la nave 3 , ha sido rebajado por debajo de la cota que presenta el firme del resto de la nave, conformando un lugar destacado por su mayor altura, así como también por la presencia de una cruz incisa en el centro de la pared oeste. Por otra parte, en el desarrollo de los trabajos de documentación arqueológica se observaron dos pequeñas mortajas rectangulares localizadas, la primera en la pared este, cerca del ángulo que conecta con la pared norte de la nave 3 y la segunda en la pared oeste. La hipótesis que se propone, en la línea de considerar este edificio como religioso, es la posibilidad de que estas muescas pudieran servir para colocar canceles que sirvieran para cerrar físicamente este espacio durante la liturgia.

Siguiendo esta misma línea de interpretación se puede establecer la posibilidad de que ciertas regularidades en la disposición de los rebajes excavados en la roca, en especial por lo que hace referencia a la posible identificación de dos formas cuadradas situadas al norte de ambos grupos de escalones, fueran las huellas en negativo que han pervivido de los soportes utilizados para instalar algún tipo de mueble, relacionado con la función original del edificio.

Finalmente, hay que señalar que al exterior de este complejo se observan algunos elementos relacionados con el mismo, como es, por ejemplo, una pila adosada a la fachada, en el tramo de muro comprendido entre las puertas de acceso a las naves I y 2. Se trata de una estructura de tipo rectangular, provista de desagüe y muy parecida a la documentada junto a la puerta del complejo rupestre 2. A esto hay que añadir la presencia de un banco corrido excavado en la roca, sobre el que se disponen un total de 10 rebajes circulares, de distintos tamaños, que tal vez pudieran corresponder a las evidencias en negativo que han dejado los mechinales realizados para colocar los made- 
ros utilizados para sostener una cubierta, a modo de porche o narthex, es decir, configurando un espacio público abierto al exterior del edificio.

En el transcurso de los trabajos de limpieza se procedió a retirar dos paredes de mampostería, pertenecientes a una casa de época contemporánea que tapaban la fachada con el objetivo de recuperar el aspecto original de esta y descubrir una hornacina excavada en la roca con unas dimensiones aproximadas de l'30 x l'20 m. Por último, en colaboración con la Escuela Taller de Vilches se procedió al cerramiento y vallado de los complejos rupestres I y 2.

\section{El complejo rupestre 2}

Este edificio se localiza igualmente en una posición central dentro del conjunto, al este del complejo rupestre I. Se configura como un edificio rectangular de una sola nave, orientada hacia el noreste, con unas dimensiones en planta de 8'40 × 2'40 m, precedida por una entrada con escalones de bajada que presenta una puerta con arco de medio punto y un pasillo de l'60 × l'40 m, en el que se observan las huellas de los cierres. El esquema de la planta y las proporciones son muy parecidas a las utilizadas en el diseño de la nave central del complejo rupestre I, lo que, sin duda, indica una relación no sólo estructural sino también, posiblemente, de carácter funcional.

La simplicidad de esta planta es acorde con la falta de elementos decorativos o funcionales, con la excepción de la presencia de tres rebajes en el lado norte de la nave, probablemente utilizados como elementos de sujeción de algunos recipientes de grandes dimensiones. También, en la pared este, muy cercana a la entrada, se ha documentado una hornacina rectangular de igual forma y dimensiones de las halladas en las "Cuevas de la Mujer" y en el exterior se ha documentado una pila cuadrangular asociada al edificio.

El estudio comparativo entre ambas construcciones, realizado a nivel de analogía formal, presenta similitudes en las plantas o coinci- dencias en los elementos particularizados y demuestra la existencia de ciertas relaciones entre ambos, hecho que queda avalado por la existencia de un camino excavado en la roca que asciende por la ladera, abriéndose en dos ramales, el primero de los cuales accede directamente al complejo rupestre I, mientras que el segundo bordea los crestones con dirección al último edificio descrito.

Finalmente, hay que señalar que entre estos dos complejos rupestres existe una escalera tallada en la roca que da acceso a la parte superior del complejo rupestre I y, desde allí, a la meseta donde se localiza el oppidum y donde se documentan en superficie cerámicas de época emiral.

\section{El complejo rupestre 3}

Conocidas tradicionalmente como las "Cuevas del Vagonero", este grupo de cuevas se localiza al oeste de los Complejos Rupestre I y 2. Su estructura responde bien a la definición de una cavidad rupestre aérea, entendida esta como un espacio de grandes dimensiones, muy superior en tamaño a la mayoría de las cavidades restantes (AZKÁRATE, 1988). En este caso se trata de un complejo de planta irregular, cerrado y de difícil ingreso, que se articula como un espacio continuo desde el que se puede acceder a tres estancias, ubicadas a diferentes alturas.

Un aspecto relevante a destacar y muy importante para la interpretación de este espacio es la intencionalidad de dificultar los accesos, lo que permitiría disponer de un lugar de refugio. Desde el exterior este se practicaría en altura a través de unas escaleras muy empinadas y estrechas, excavadas en la roca, que sólo permiten el paso de una persona; el sistema se completa con la instalación en la parte superior de una trampilla de madera, atrancada con palos, que permitiría cerrar el hueco de la escalera.

El espacio es continuo, concebido como un largo pasillo, de una longitud aproximada de 15 $m$ y con una anchura variable, siendo la máxima alcanzada de 2'5 m. La estancia I, localiza- 
da en el extremo oeste, cierra por este lado el conjunto. Presenta una planta irregular, compuesta por un corredor de acceso, precedida por varios escalones, que se ensancha para dar lugar a un espacio de forma semicircular. En esta estancia se abre un ventanuco que mira a la vega del río Guadalimar, esto junto a la presencia de un banco corrido de forma semicircular y una mesa central, ambos elementos excavados en la roca, explica su interpretación como un oratorio.

Las dos estancias restantes se localizan en un plano superior, ambas presentan la misma planta de forma ovalada y dimensiones muy aproximadas, así como huellas interiores de cierre. La estancia 2 consta de una entrada en vertical y carece de una estructura permanente para el acceso, lo que hace pensar en que se utilizara algún tipo de escala móvil. Por el contrario, la estancia 3, ubicada en el extremo este del edificio, posee una escalera de acceso excavada en la roca. Otra característica diferencial entre ambos espacios es que el primero posee un gran ventanal que mira hacia la vega del Guadalimar y que proporciona una iluminación natural, mientras que la última sólo presenta dos pequeños vanos que no proporcionan mucha luz. Por otra parte, la iluminación interna de este complejo rupestre se completaría con luz artificial que proporcionarían las antorchas colocadas en los agujeros de sección cónica excavados a distintas alturas en las paredes de la estancia 1.

La reutilización de este conjunto como vivienda, en época contemporánea, es visible por lo que respecta al cierre con muros de tapial de algunos vanos situados en el primer sector del corredor del pasillo, así como por la presencia de una hornacina localizada en el ángulo noreste de este primer sector del corredor que, hasta hace poco tiempo, albergó una imagen, probablemente la manifestación de una tradición religiosa popular que se remonta a la función primitiva a la que se dedicó este complejo. En esta línea habría que interpretar, seguramente, la presencia de una cruz latina sobre un triángulo incisa en una de las paredes.

\section{El complejo rupestre 4}

Este último conjunto se localiza en el extremo este del farallón de Giribaile. A diferencia de las denominadas "Cuevas del Vagonero", a este complejo se podía acceder desde el nivel de base. Se compone, a modo de colmena, por un conjunto de pequeñas habitaciones, excavadas en la roca, cubiertas con bóvedas de cascarón o cupuliformes y estructuradas en tres niveles, comunicadas entre sí interiormente y con ventanas que miran al valle.

En la actualidad, el frente del complejo rupestre está abierto debido al desplome de la roca de soporte, a causa, muy probablemente, de la acción del agua sobre la piedra, por lo que el trabajo en esta zona ha sido muy complicado debido a la peligrosidad del acceso actual a la misma y resulta casi imposible establecer la posible existencia de rozas y mechinales correspondientes a estructuras mixtas y de elementos interiores característicos de esta clase de habitáculos tales como los poyos-lechos o, incluso, de pequeños oratorios asociados.

\section{LA NECRÓPOLIS DE LAS CASAS ALTAS}

En el límite norte del olivar que se localiza a las espaldas del cortijo de las Casas Altas, junto a una necrópolis de época ibérica, se ha documentado un grupo de tumbas que, probablemente, haya que poner con relación a los pobladores de las cuevas. Se trata de una zona de enterramiento de la que ya se tenían noticias gracias al informe de unas prospecciones efectuadas en el término municipal de Vilches en 1986, en el que se describen una serie de estructuras de grandes lajas de piedra caliza, encofradas en la roca o, simplemente, excavadas en tierra que, ensambladas unas con otras, formaban construcciones rectangulares de unos $3 \mathrm{~m}$ de longitud por 0'5 m de anchura, mientras que un segundo tipo estaría formado por las sepulturas excavadas directamente en la roca y selladas con lajas de caliza (GÁMEZ, 1986).

En el reconocimiento del sitio se han documentado tres de estas sepulturas, aunque sólo 
hace falta un simple paseo por el terreno para darse cuenta de que los restos son mucho más numerosos y que presentan un estado de conservación lamentable. Las localizadas por nosotros hasta ahora se corresponden con el segundo de los tipos descritos, tumbas excavadas en la roca y cubiertas por lajas de piedra plana que aparecen dispersas en superficie junto a los propios enterramientos. En un caso la tumba presenta resaltes para encajar mejor las tapas.

Otro dato de interés viene dado por la propia alineación de los enterramientos que sigue, básicamente, una orientación este-oeste, aunque se observa una tendencia a girar en dirección noroeste-sureste, adaptándose a la propia topografía del terreno, un espolón de roca configurado a partir de una línea de ruptura abrupta que destaca sobre la vaguada de un antiguo arroyo.

La tipología formal de las tumbas y su orientación nos remite a paralelos tardorromanos y/o altomedievales excavados y publicados recientemente en diferentes lugares de la provincia de Jaén, entre los que se encuentran las necrópolis de Toya (DÍAZ, PORTERO, 2003) o de Marroquíes Bajos (SERRANO, CASTILLO, 2000), pertenecientes a comunidades hispano-visigodas o emirales.

De esta necrópolis, tal vez proceda una vasija de barro depositada en el Museo Arqueológico Provincial de Granada y registrada con el número de inventario 1348, que ingresó en dicha institución como parte de la colección Manuel de Góngora. Esta pieza, aparentemente, es muy similar a otros ejemplares procedentes de necrópolis visigodas como la del Barranco del Lobo en las subbéticas cordobesas (VAQUERIZO et alii, 1994). Por otra parte, sobre el terreno, actualmente, es posible observar la presencia de fragmentos de tejas, que podrían haber sido utilizadas, junto con las piedras planas, como elementos de cubrición de las tumbas.

Aparte de estos enterramientos localizados junto al cortijo de las Casas Altas, no descartamos la hipótesis sobre la existencia de enterramientos situados en el entorno más próxi- mo a la entrada del posible templo, ya que durante los trabajos de limpieza y acondicionamiento de los caminos de acceso a las cuevas se documentaron numerosos rebajes intencionales realizados en la roca, aunque por el momento no ha sido posible localizar ningún enterramiento.

\section{PIEDRA HUECA GRANDE Y PEQUEÑA}

Se trata de dos covachas excavadas por erosión diferencial en la arenisca y situadas una junto a la otra al norte de la meseta de Giribaile, en la vertiente opuesta al lugar donde se localiza el farallón que ha proporcionado los complejos rupestres analizados en este trabajo. Ambas presentan una planta de tendencia semicircular y cazoletas en la parte superior que permiten, a través de un sistema de canales, recoger el agua de lluvia en la base. Estas covachas son conocidas gracias a la investigación prehistórica desarrollada en la zona a finales de los años 60 y comienzos de la década de los 70 (MORENO, 1967) y la decisión de incluirlas en la actividad arqueológica que hemos realizado se debe al interés que despierta el estudio y la documentación de los signos grabados en su interior, entre los que se encuentran motivos cruciformes (enmarcados, con peana, etc.), interpretados como símbolos antropomorfos (ídolos cruciformes, ídolos paleta, etc.) que, inicialmente, se incluyeron como manifestaciones rupestres esquemáticas, más o menos contemporáneas o posteriores a la Edad del Bronce, aunque esta lectura dejaba abierta una cierta ambigüedad cronológica y cultural, reconociendo su cercanía formal con otros grabados presentes en edificios monumentales que abarcaba un arco temporal que iba desde el Prerrománico hasta el Barroco, sin descartar la posibilidad de que estos grabados pudieran ser obra de pastores o eremitas (FORTEA, 1970-1971). El debate sobre la correcta adscripción cultural de esta clase de representaciones continua hasta la actualidad, tal y como demuestra el hecho de incluir Piedra Hueca como un enclave más en la dispersión de los grabados rupestres post-paleolíticos al aire libre en la Península Ibérica (GÓMEZ-BARRERA, 1993). 
En nuestra opinión estos signos grabados deben interpretarse con relación al estudio del poblamiento rupestre documentado en el entorno de la meseta de Giribaile. Esta postura que intenta contextualizar el análisis de la iconografía en el territorio, permite realizar una lectura de los símbolos cruciformes no como representaciones de antropomorfos prehistóricos, si no, más bien, como manifestaciones religiosas de simbología cristiana, entre los que se cuentan diversos motivos, destacando entre ellos el tipo de cruces griegas inscritas en un círculo, bien conocidas a través de las estelas discoideas de la meseta (véase por ejemplo, PASCUAL MAYORAL, PASCUAL MAYORAL, 1999), O las representaciones de cruces latinas con peana de forma triangular, a veces con dos brazos horizontales. Dentro de este último grupo habría que añadir las dos cruces, con peana triangular o circular, que ocupan una posición destacada, en el lugar que define el eje de simetría de los complejos rupestres 3 y I, respectivamente.

Actualmente, los grabados presentan un estado de conservación muy malo, al encontrarse cubiertos por varias capas de hollín, debido a la acción del fuego realizado dentro de las covachas durante años. Nuestra intención a la hora de incluir las dos covachas de Piedra Hueca en este estudio no es tanto la de resolver una larga polémica, si no abordar las cuestiones interpretativas que permiten vincular este conjunto con los complejos rupestres documentados en el farallón de Giribaile.

\section{INTERPRETACIÓN HISTÓRICA}

La inexistencia de depósitos arqueológicos en las Cuevas de Giribaile, como resulta habitual, por otra parte, cuando se trabaja con esta clase de construcciones excavadas en la roca, condiciona la metodología empleada y dificulta la interpretación histórica, debiendo recurrir a la comparación por analogía formal con otros complejos rupestres similares o cercanos y a una lectura contextual y diacrónica de los patrones de ocupación del territorio.

Aunque no se aporte una cronología precisa del conjunto documentado, si se pueden apuntar una serie de rasgos, entre los cuales cabe citar la posible existencia de una iglesia y un oratorio, de un hábitat rupestre, de espacios de reunión, de cruces y símbolos grabados en las paredes, etc., característicos de un poblamiento eremítico, vinculado a unas comunidades cristianas que, grosso modo, se enmarcan en época altomedieval.

El estudio del entorno geográfico y paisajístico también resulta determinante a la hora de explicar el modo en el que se originó y desarrolló este tipo de poblamiento, mostrando unas condiciones muy favorables para una forma de vida que propicia un clima de oración, soledad y recogimiento y, por consiguiente, facilita el ideal de la fuga espiritual de lo mundano. Este hecho no es opuesto a la implantación de eremitorios cerca de poblaciones o vías de comunicación, aunque resultan casos excepcionales. Al respecto de esto último se debe señalar la existencia en el entorno de Giribaile de evidencias arqueológicas con relación a una ocupación del campo en época tardorromana y/o visigoda y de un camino cercano que transcurre a los pies del oratorio de Valdecanales, el Camino a Toledo, de posible origen altomedieval, señalado en los mapas topográficos actuales.

En el caso de Giribaile, a la existencia de roquedos de piedra blanda que facilitaron la excavación de estas cuevas, en las que aún se conservan las huellas de picos retocados posteriormente con cincel, se sumaba la disponibilidad de nacimientos de agua y zonas aptas para el cultivo, garantizando de esta forma unas condiciones mínimas para la subsistencia.

El poblamiento que se asocia a las Cuevas de Giribaile parece corresponder a una comunidad unida por vínculos religiosos y lazos de cohesión específicos, basados en normas de convivencia establecidas y en algún tipo de jerarquía. Siguiendo el ejemplo de otros modelos bien conocidos, aunque distantes, el movimiento eremita inicial pudiera tener un origen individual y espontáneo, mientras que la articulación y vertebración final de los espacios construidos y ocupados podría responder a las pautas de comportamiento de una comunidad 
semieremítica (PUERTAS, 1966). Algunos aspectos concretos presentes en el complejo rupestre 3, tales como la dificultad en los accesos, que remite a la idea de un cierto encastillamiento, y la utilización de cierres móviles en el suelo, a modo de empalizada vertical, que permitirían dejarlo completamente aislado, parecen signos indicativos del uso de este complejo durante épocas de persecución, especialmente intensas por lo que respecta a las comunidades cristianas mozárabes.

Respecto a una posible lectura funcional de los diversos espacios documentados, no debería presentar problemas la adscripción como eremitorio del complejo rupestre catalogado con el número 4, en el que los habitáculos se organizan por pisos. En el caso de Giribaile el hábitat sigue el modelo más común de eremitorio, formado por un número variable de celdas apiñadas, localizadas cerca de una iglesia. Se trata de construcciones sencillas, de perfil curvo, horadadas en la roca a diferentes alturas, que constituirían viviendas individuales. A este complejo rupestre habría que añadir la existencia de cuevas distanciadas del grupo, Piedra Hueca Grande y Pequeña. Su simplicidad y su aislamiento invitan a la meditación, a la soledad y al recogimiento necesario para favorecer el encuentro espiritual, la esencia primera del eremitismo, que se completa con espacios de reunión, de carácter colectivo, que conjugan la vida en comunidad.

Por el momento no ha sido posible establecer el tamaño de esta comunidad a partir de una lectura del número total de celdas, ya que tenemos noticias de la existencia de otro grupo de estancias de características similares a la estudiadas, probablemente localizadas en el extremo oeste del farallón, noticias que no han podido ser corroboradas por problemas de inaccesibilidad en la zona.

Tradicionalmente, el complejo rupestre I se ha identificado con una iglesia o con un lugar de culto litúrgico. Una aproximación inicial a su arquitectura y el entorno en el que se ubica parecen avalar dicha hipótesis, tanto la posición central que este edificio ocupa en el farallón, rodeado de celdas, como la elección de su emplazamiento, en una zona de fácil acceso, además de la presencia de una cruz incisa en el lugar que marca el centro de simetría del edificio, allí donde debería localizarse el presbiterio, y la existencia de oquedades y ranuras en el cruce de las dos naves principales, que pudieran haber servido para apoyar estructuras ligeras o, incluso, canceles que sirvieran para cerrar este espacio en determinados momentos de la celebración o tiempos litúrgicos, sin olvidar la existencia en las naves laterales de hornacinas de forma arqueada a las que no se puede atribuir una funcionalidad concreta, pero que pudieron servir para colocar lámparas o algún tipo de objetos sagrados utilizados en la liturgia, como si de credencias se tratase, son algunos rasgos que pueden relacionarse con el diseño y la arquitectura de las basilicas rupestres altomedievales (MONREAL, 1989), aunque ninguno de ellos, por sí mismo, resulta definitivo.

Incluso, si aceptamos el carácter basilical de este conjunto, resulta difícil realizar una lectura funcional a partir del estudio de la planta, debido a las importantes variaciones que presenta este tipo de edificios. La comparación con el conjunto de iglesias prerrománicas hispánicas de los siglos VIII a Xl, sobre la que se ha realizado un ensayo de tipología arquitectónica recientemente (PUERTAS, 1999-2000), muestra elementos comunes y diferenciadores que hace difícil encuadrar el complejo rupestre I en un grupo concreto, más allá de su adscripción inicial a las iglesias rupestres, al que debemos considerar, por otra parte, el más heterogéneo de todos ellos. El hecho de presentar dos espacios intermedios (naves 2 y 4 ) de separación entre las naves principales, que tal vez deberíamos interpretar como estancias en las que se preparaban las ofrendas, y no marcar de forma clara la existencia de un ábside o de un coro diferenciado en planta, ni exterior, ni interiormente (con un arco triunfal, con un muro iconostático, sobreelevando este espacio con respecto al resto de las naves, etc.), son rasgos particulares difíciles de interpretar.

Por otra parte, resulta sorprendente la simetría y el equilibrio en las proporciones, al tratarse de un edificio excavado completamente en la roca ya que, habitualmente, esta clase de 
iglesias rupestres se corresponde con construcciones arquitectónicamente más sencillas que las proyectadas para ser realizadas en obra de fábrica. A este respecto resulta interesante recordar que este hecho debería ponerse con relación al desconocimiento de las primitivas plantas de las iglesias altomedievales en el sur de la Península Ibérica, frente al grupo que se define al norte de la meseta, principalmente en las cuencas del Duero y el alto Ebro, mucho más evolucionado (RIU, 1972).

El desarrollo horizontal de la estructura resulta poco habitual, aunque puede estar enmascarando un primitivo edificio de una sola nave (la que hemos denominado como 3), es decir, sin crucero, que con el paso del tiempo se transformara en una iglesia "monástica" de planta basilical compleja, en la que se diferenciara un espacio específico dedicado al coro, ampliando la planta inicial con un transecto y con las naves I, 2, 4 y 5, que siguen, como se ha repetido en varias ocasiones, un mismo módulo. Es en este punto cuando resulta difícil decantarse por la continuidad en el uso religioso del edificio o el cambio hacia una funcionalidad de hábitat. Hay que tener en cuenta, con relación a esta idea, que a partir de las décadas centrales del siglo $X X$ se establecieron entre 40 y 50 familias, reaprovechando los distintos complejos rupestres, según consta a través de comunicaciones orales, aunque aún queda por realizar un importante trabajo de recuperación de esta memoria histórica.

A este lugar, de carácter público y accesible, al que se une el complejo rupestre 2, que podría servir de lugar de reunión para realizar todas aquellas actividades en común que habitualmente se llevan a cabo fuera de la iglesia tales como asambleas, comidas de fraternidad, etc, se le contrapone el complejo rupestre 3, con un carácter mucho más privado (celdas colgadas, tablas horizontales dispuestas como cierre del conjunto, etc.), articulado a partir de varias cámaras individualizadas y localizadas a diversas alturas, que se organizan en torno a un espacio central que cumple la función de distribuidor. Dentro de este complejo resulta difícil interpretar la presencia en la estancia I de un banco corrido adosado a la pared del edificio y excavado en la propia roca, que rodea una mesa labrada también en la roca que, tal vez, pudiera interpretarse como un altar de bloque sin lipsanoteca, que en todo caso define un espacio de reunión, al que tradicionalmente se ha considerado como un oratorio.

Estas diferencias en organización y distribución entre ambos complejos pueden indicar la complementariedad de diferentes espacios que cumplan funciones concretas, difíciles de determinar desde la arqueología e insertas en un movimiento cristiano que no puede ser precisado en el tiempo, más allá de su pertenencia a un momento indeterminado altomedieval, y que quedaría caracterizado por un hábitat en el que el grupo se define como una comunidad semieremítica, basada en unos principios comunitarios que recuerdan la fórmula de las antiguas lauras y que servirían para explicar la complejidad del conjunto rupestre, en la que se combinan covachas aisladas, con cavidades rupestres de estancia única y cavidades aéreas, sin descartar lugares destinados a reunión y una posible basilica, recordando ejemplos paradigmáticos como Las Gobas (AZKÁRATE, 1991). Esto es, simplemente, por el momento, una hipótesis a tener en cuenta.

\section{BIBLIOGRAFÍA}

ASENJO, C. (1990): Las cuevas. Un insólito hábitat en Andalucía Oriental. Sevilla.

AZKÁRATE, A. (1988): Arqueología cristiana de la Antigüedad Tardía en Álava, Guipúzcoa y Vizcaya. Servicio de Publicaciones de la Diputación Foral de Álava, Vitoria.

AZKÁRATE, A. (|99|): "El eremitismo de época visigótica. Testimonios arqueológicos". Cuarto Seminario sobre el Monacato, Codex Aquilarensis, Cuademos de Investigación del Monasterio de Santa María la Real. No 5, pp. I4 I-179.

BARRIONUEVO, L. ( 1986): "Cuevas artificiales en el Reino de Granada". Revista de Arqueología. N 62, pp. 16-24.

BERTRAND, M. (1986): "El hábitat troglodítico antiguo en la Hoya de Guadix (Granada). Elementos de tipología". Arqueología Espacial. N 10, pp. 263-283.

CASAS, C. (2000): "Dos oratorios rupestres en la Loma: Valdecanales y la Veguilla (Rus, Jaén)". Visitas al Patrimonio Histórico Provincial de Jaén 94/99. Jaén, pp. I 54- 158. 
CASTILLO, J.C. (1997): "Vilches, guardián de los pasos de Sierra Morena". Pueblos y Ciudades. N I36. Jaén, pp. 27||-27|3.

CHOCLÁN, C. (1986): Informe sobre la actividad arqueológica desarrollada en el campo de trabajo de Giribaile. Texto inédito.

DÍAZ GARCÍA, M.j:; PORTERO, V. (2003): "La necrópolis tardorromana de Toya, Peal de Becerro (Jaén)". Arqueología y Territorio Medieval. № 10.1, pp. I 19-135.

FORTEA, J. (1970-197|). "Grabados rupestres esquemáticos en la provincia de Jaén". Zephyrus. Volumen XXIXXII, pp. 139-157.

GÁMEZ, J.T. (1986): Informe de las prospecciones sistemáticas efectuadas en el término municipal de Vilches durante el mes de julio de 1986. Texto inédito.

GÓMEZ-BARRERA, J.A. (1993): "Tradición y continuidad del arte rupestre en la Antigüedad Tardía". La Cueva de la Camareta (Agramón, Hellín-Albacete), Antigüedad y Cristianismo. Volumen X, pp. 433-448.

GÓNGORA, M. (1916 [1860]): "Viaje literario por las provincias de Jaén y Granada". Don Lope de Sosa 1916. Parte 9, pp. 5-8.

GUTIÉRREZ, L.M. (1998): El poblamiento ibérico en el curso medio del río Guadalimar. Tesis doctoral en microfichas. Servicio de Publicaciones de la Universidad de Jaén, Barcelona.

GUTIÉRREZ, L.M. (2002): El oppidum de Giribaile. Servicio de Publicaciones de la Universidad de Jaén.

GUTIÉRREZ, L.M.; RUEDA, C.; LUNA, M.B.; DÍAZ GARCÍA, M.J. (2004): "Prospección arqueológica y estudios previos para la puesta en valor de las Cuevas de Giribaile (Vilches, Jaén)". Anuario Arqueológico de Andalucía del año 200I. Volumen II, pp. I75-I80.

HAUSCHILD, T.; SCHLUNK, H. ( 1970): "Die Höhlenkirche beim Cortijo de Valdecanales". Madrider Mitteilungen. $N^{\circ}$ I I, pp. 223-23।

MONREAL, L.A. (1989): Eremitorios rupestres altomedievales (el alto valle del Ebro). Cuadernos de Arqueología de Deusto. N 12. Bilbao.

MORENO, J. (1967): "Grabados rupestres en las Cuevas de Vilches". Boletín de la Real Academia de Córdoba de Ciencias, Bellas Letras y Nobles Artes. No 87, pp. I83-I 86.
NAVASCUÉS, J.M. (1970): "El oratorio de Valdecanales (Jaén)". Boletín de la Real Academia de Bellas Artes de San Fernando. $\mathrm{N}^{\circ} 31$, pp. 82-84.

NOCETE, F.; CRESPO, J.M.; ZAFRA, N. (1986): "Cerro del Salto. Historia de una periferia". Cuadernos de Prehistoria de la Universidad de Granada. No II, pp. 171-198.

PASCUAL MAYORAL, M.A.: PASCUAL MAYORAL, M.P. (1999): "Estelas discoideas de La Rioja". Los columbarios de La Rioja, Antigüedad y Cristianismo. Volumen XVI, pp. 3/3-368.

PUERTAS, R. (1966): "El eremitismo rupestre en la zona de Nájera". IX Congreso Nacional de Arqueología (Valladolid, 1965). Zaragoza, pp. 419-430.

PUERTAS, R. (1999-2000): "Iglesias prerrománicas hispánicas (siglos VIII al XI). Ensayo de tipología arquitectónica". Mainake. Volumen XXI-XXII, pp. I39- 195.

RIU, M. (1972): "Cuevas-eremitorios y centros cenobíticos rupestres en Andalucía Oriental". VIII Congreso Internacional de Arqueología Cristiana (Barcelona, 1969). Pontificio Istituto di Archeologia Cristiana-CSIC, Ciudad del Vaticano-Barcelona, pp. 43I-443.

RUIZ RODRÍGUEZ, A.; MOLINOS, M. (1993): Los iberos. Análisis arqueológico de un proceso histórico. Crítica, Barcelona.

RUIZ RODRÍGUEZ, A.; MOLINOS, M.; GUTIÉRREZ, L.M.; BELLÓN, J.P. (200I): "El modelo político del pago en el alto Guadalquivir (ss. IV-III a.n.e.)". Taula Rodona celebrada a Ullatret: Territori polític i territori rural durant I'Edat del Ferro a la Mediterrània Occidental, Monografies d'Ullastret. $\mathrm{N}^{\circ} 2$, pp. I I-22.

SERRANO, J.L.; CASTILLO, I.C. (2000): "Las necrópolis medievales de Marroquíes Bajos (Jaén). Avance de las investigaciones arqueológicas". Arqueología y Territorio Medieval. № 7, pp. 93-120.

SERVAJEAN, F.; SERVAJEAN, G.; CASTILLEJO, A. (1986): "De Giri a Giribaile. Análisis de una posible correspondencia entre Giri y Guiribaile". Boletín de la Asociación Española de Amigos de la Arqueología. N²2, pp. 37-46.

VAÑÓ, R. (1970): "Oratorio rupestre visigodo del Cortijo de Valdecanales, Rus (Jaén)". Madrider Mitteilungen. $N^{\circ}$ । I, pp. 213-222.

VAQUERIZO, D.: QUESADA, F.; MURILLO, J.F.; CARRILLO, R.; CARMONA, S. (1994): Arqueología cordobesa. Almedinilla. Universidad de Córdoba-Ayuntamiento de Almedinilla. 


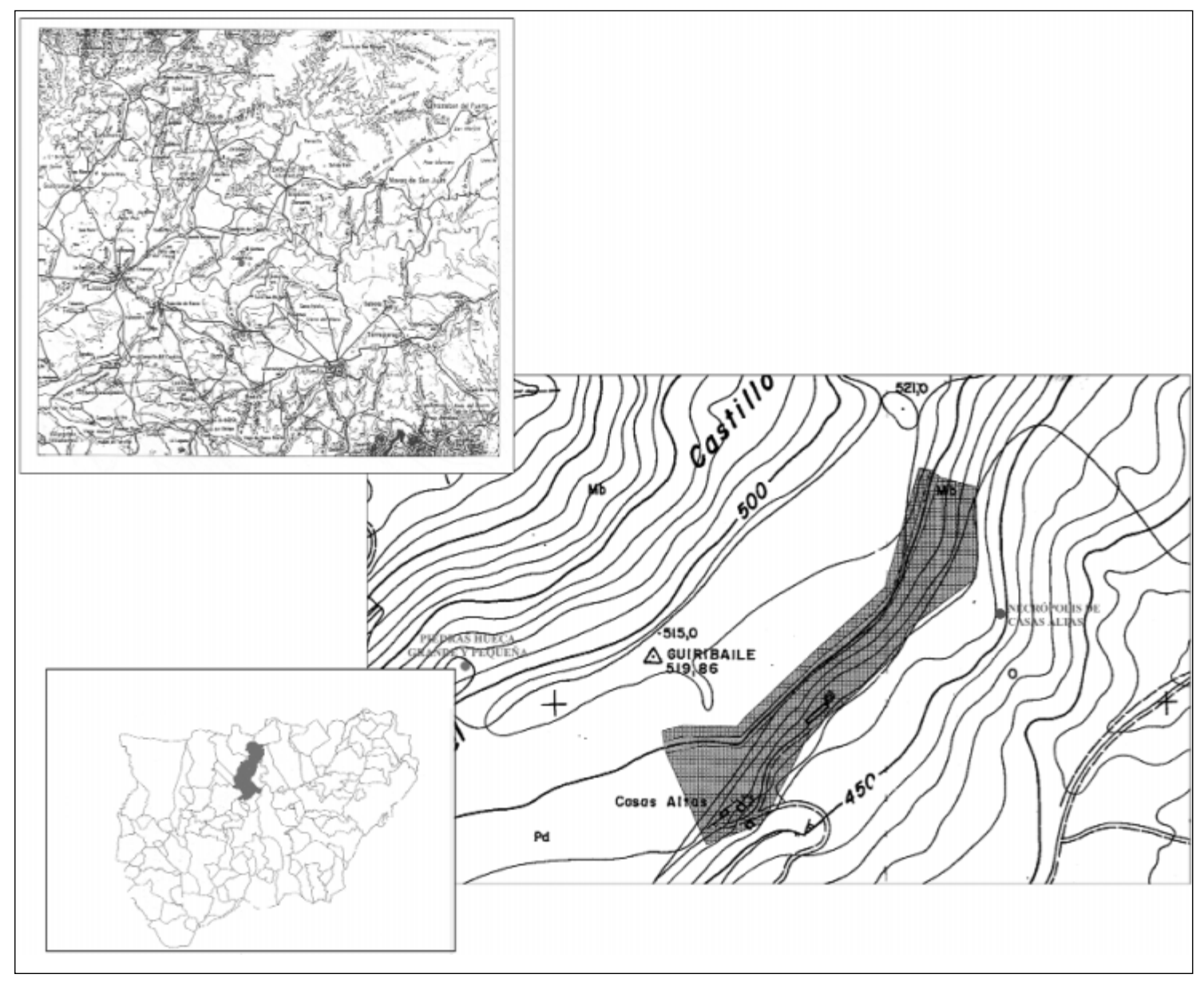

Fig. I. Plano de situación de Giribaile. 


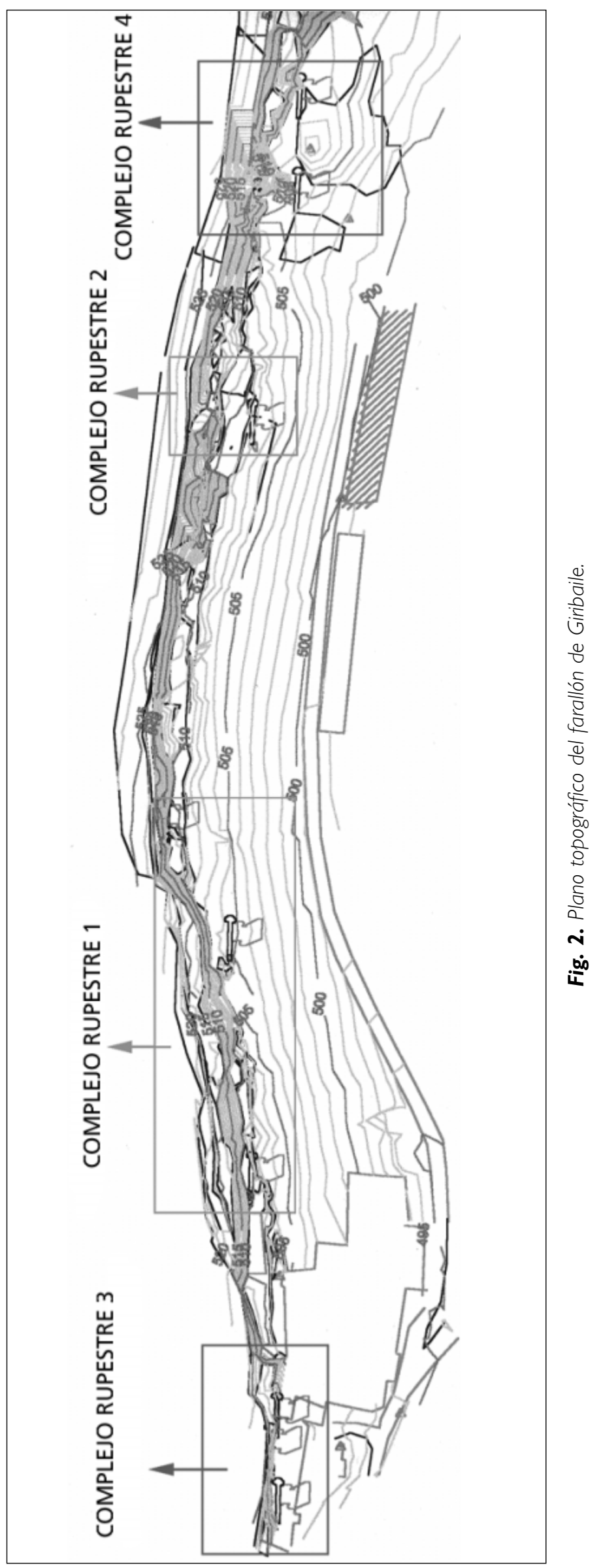




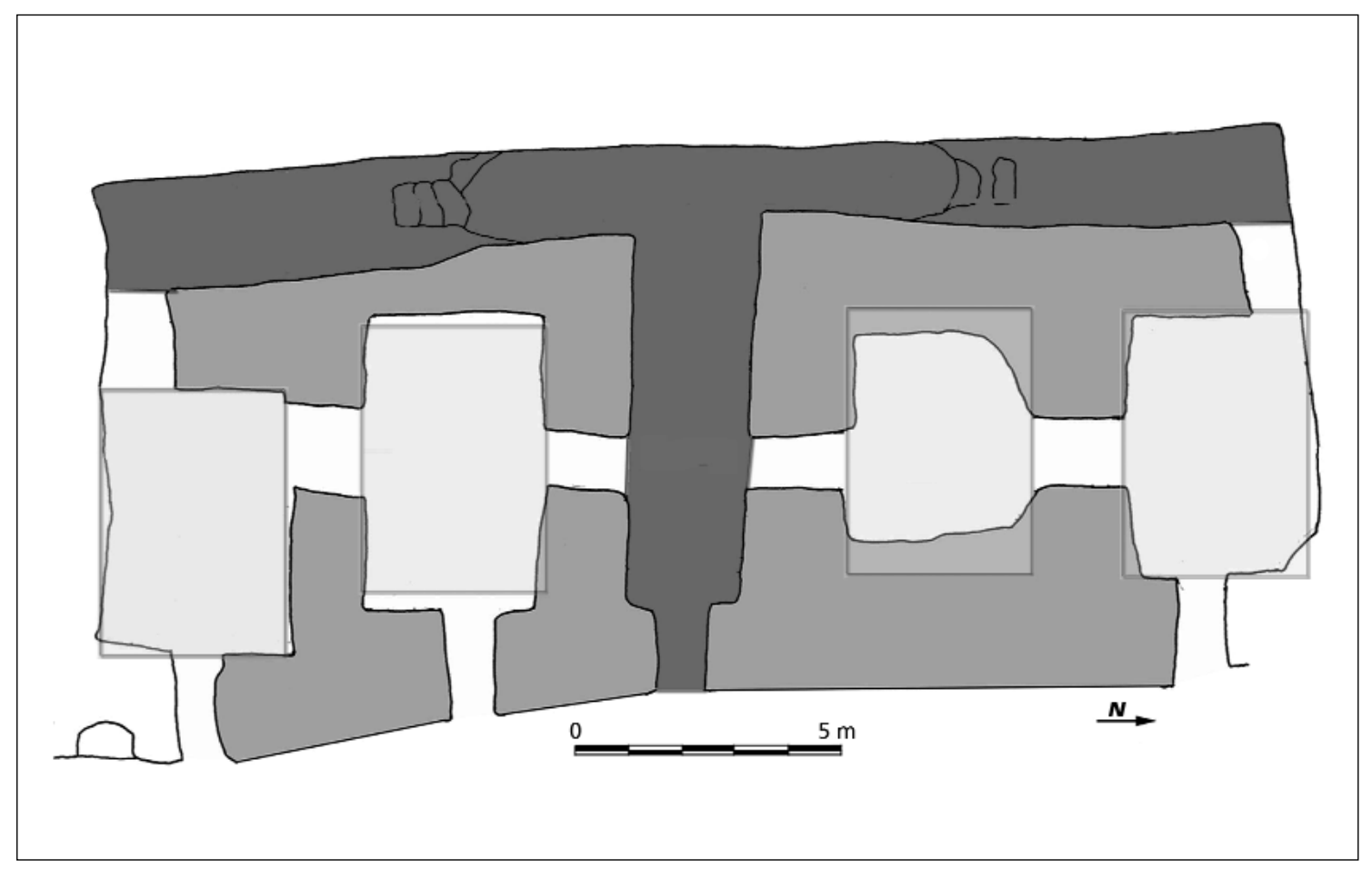

Fig. 3. Módulos empleados en el complejo rupestre 1 .

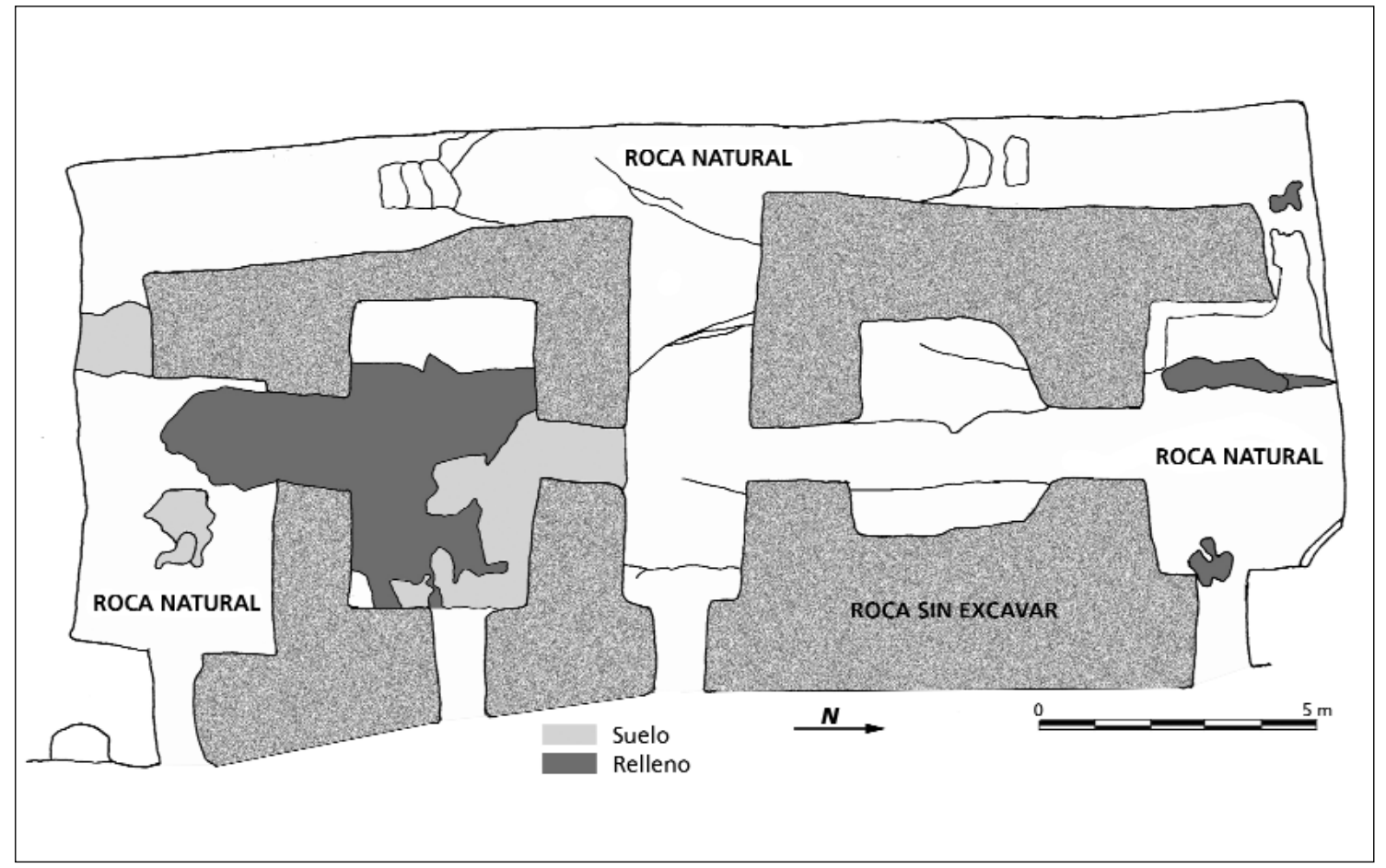

Fig. 4. Complejo rupestre I. Localización de la roca natural y zonas de relleno. 


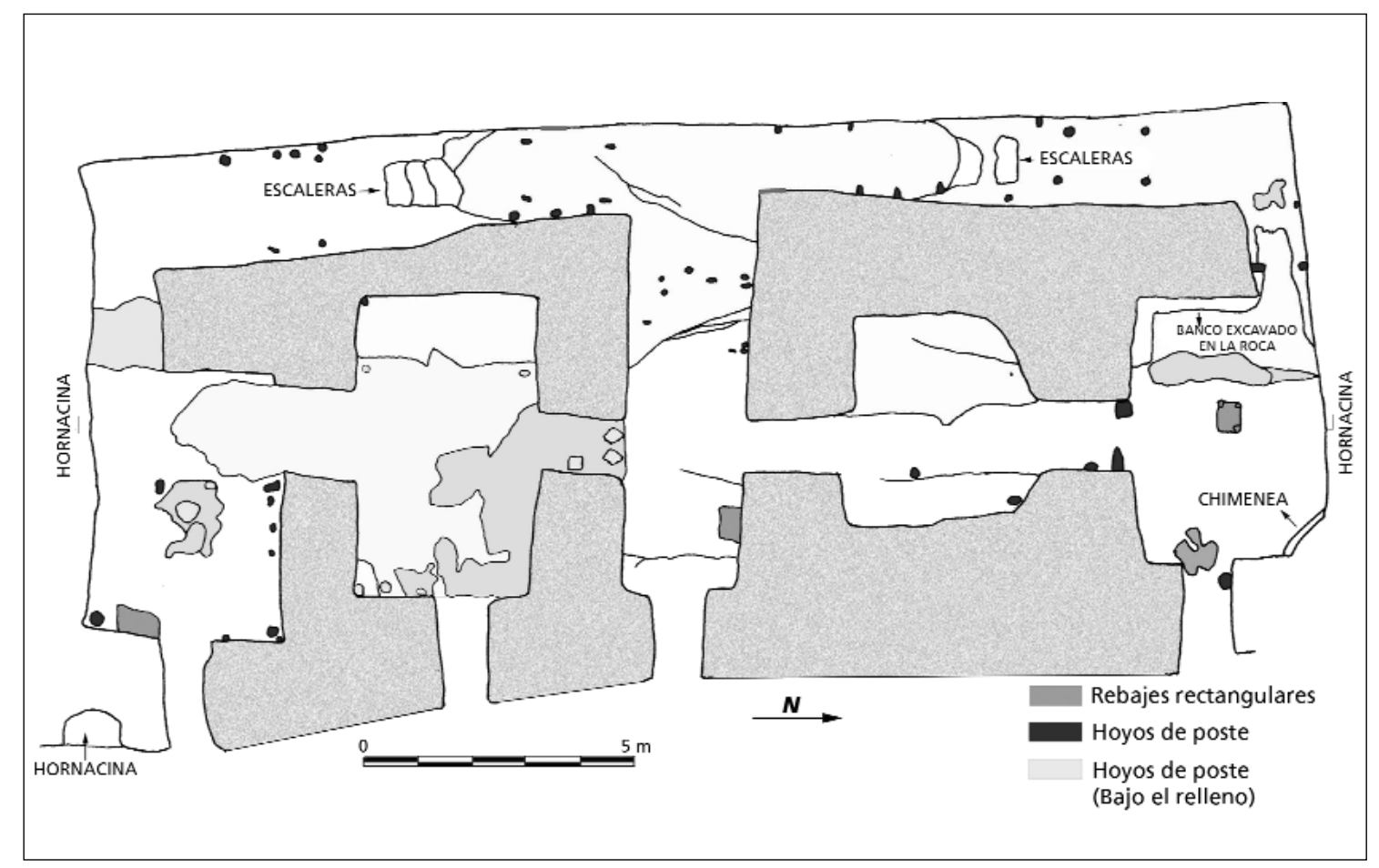

Fig. 5. Complejo rupestre I. Unidades estructurales construidas.

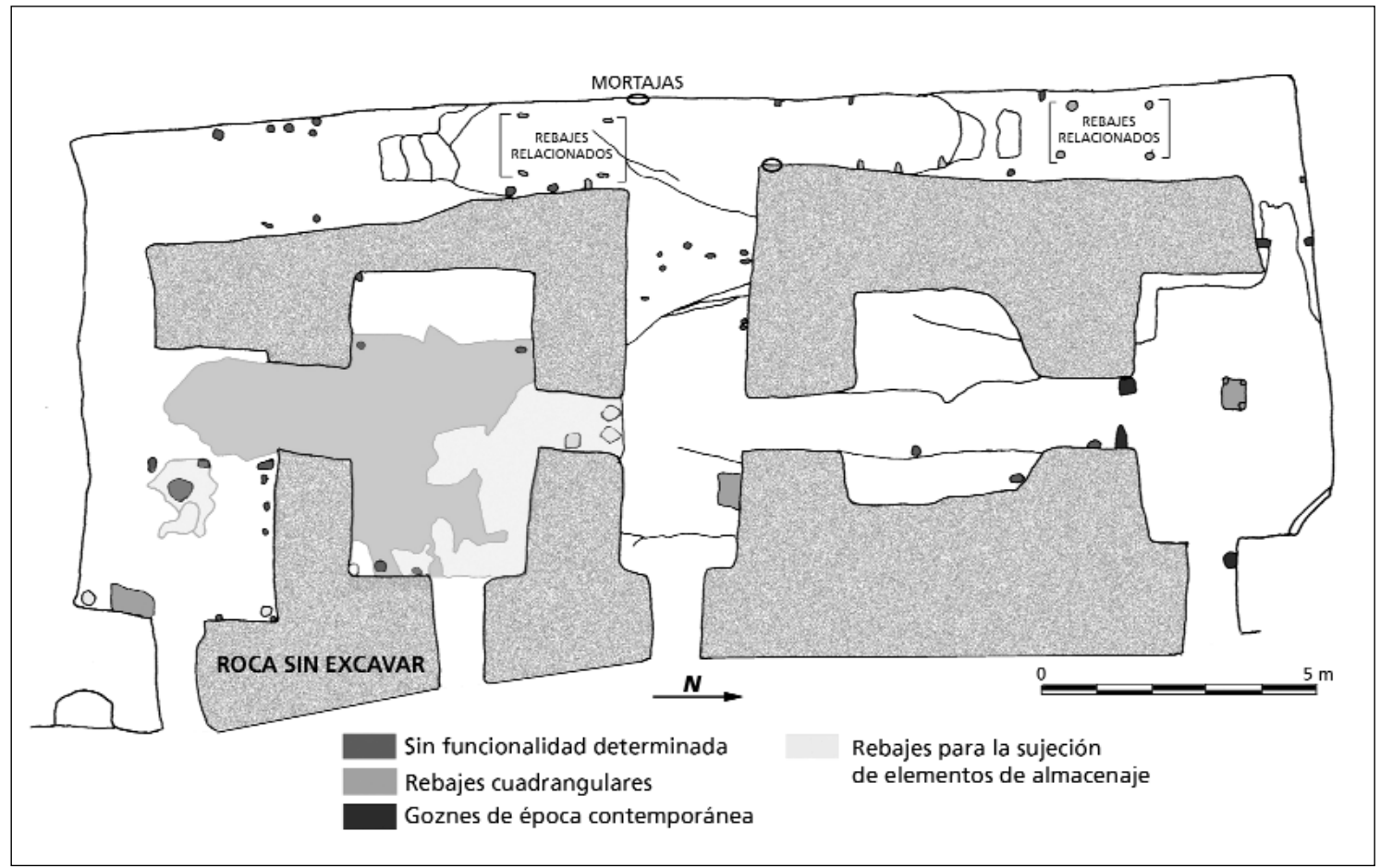

Fig. 6. Complejo rupestre I. Funcionalidad de las unidades estructurales construidas. 


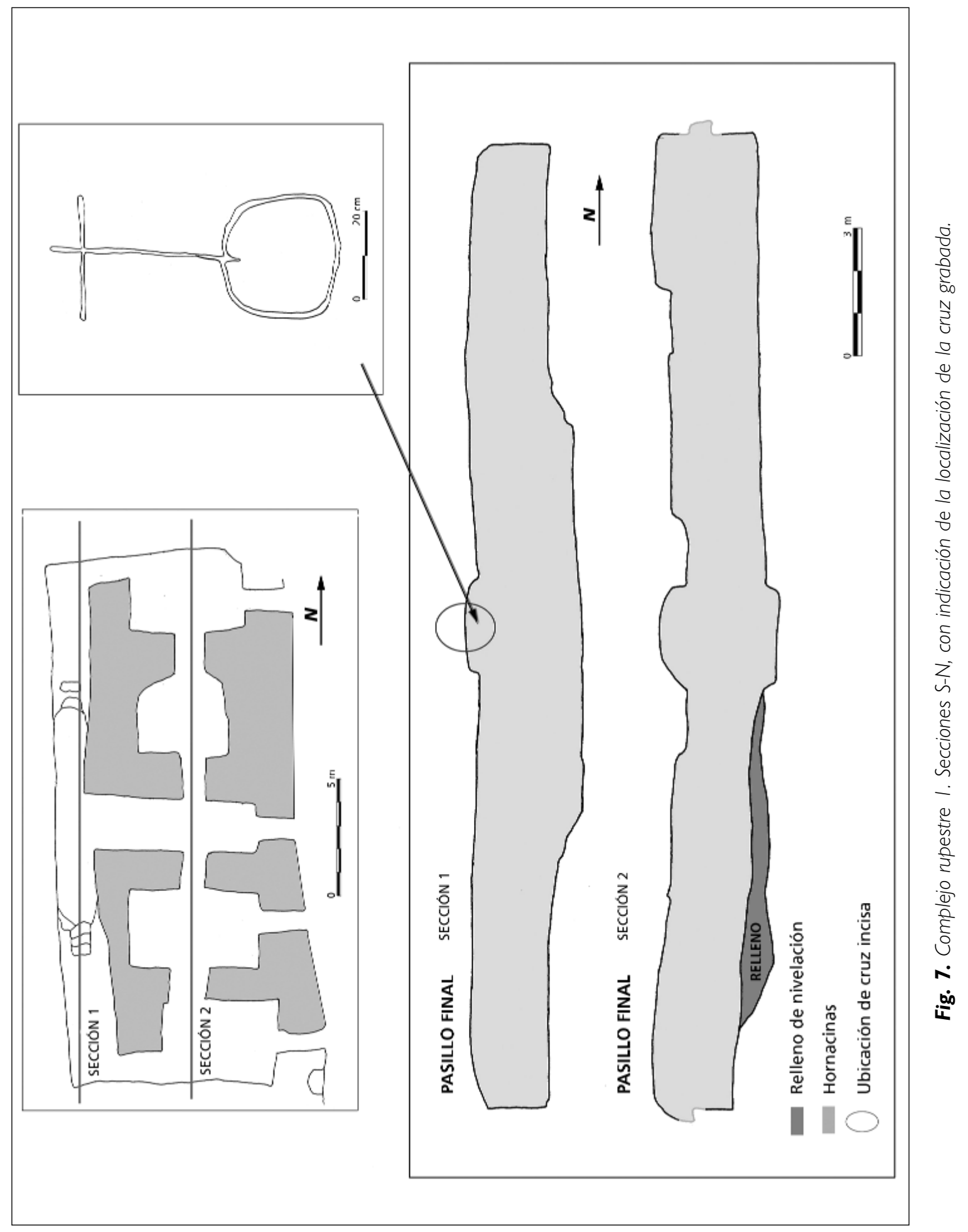




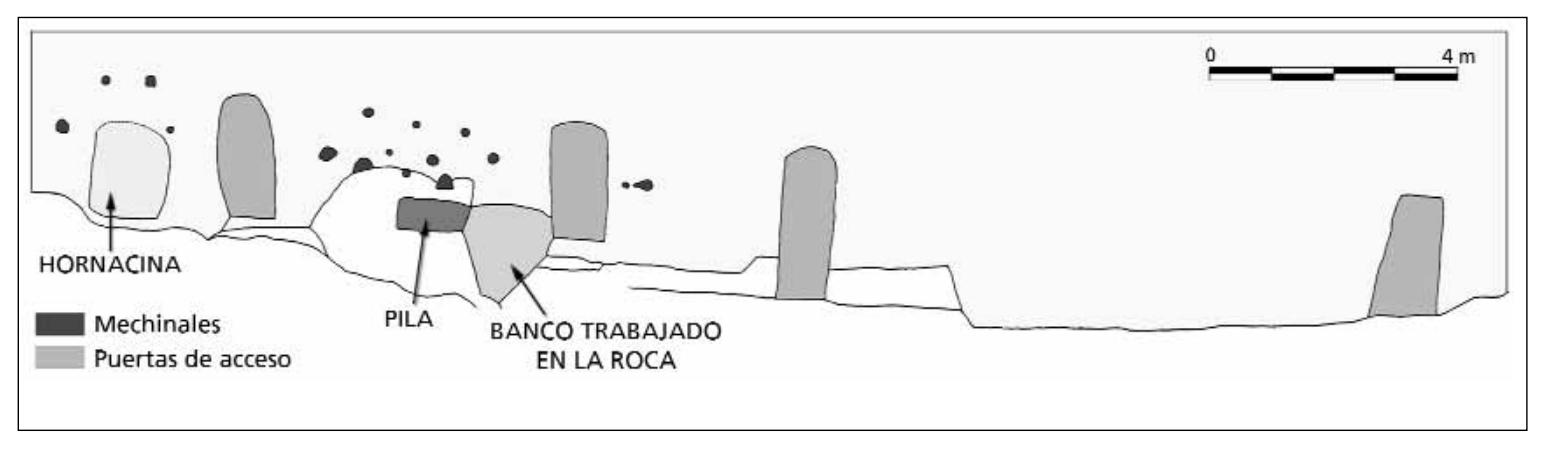

Fig. 8. Complejo rupestre I. Dibujo de la fachada.

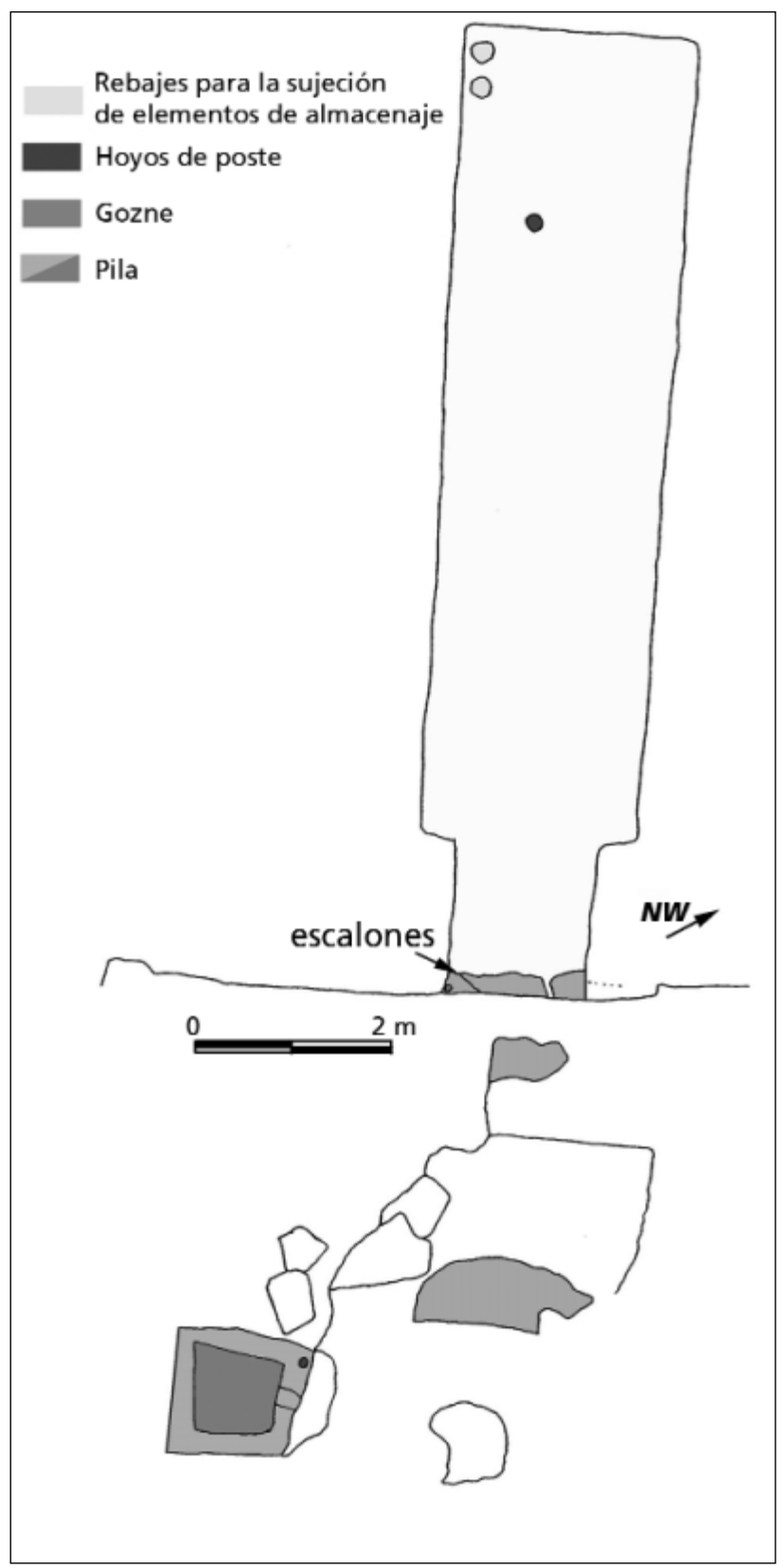

Fig. 9. Complejo rupestre 2. Planta. 


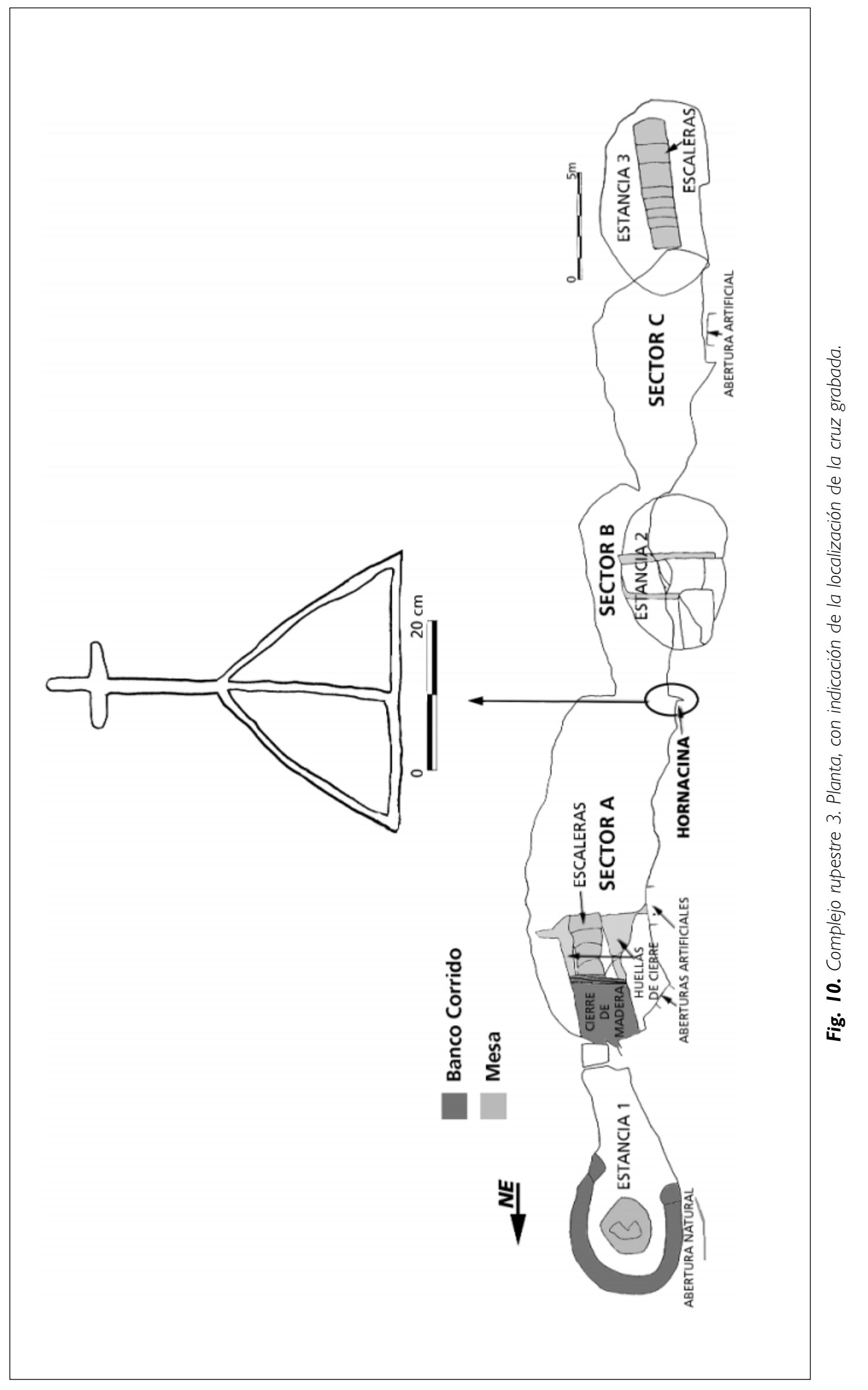




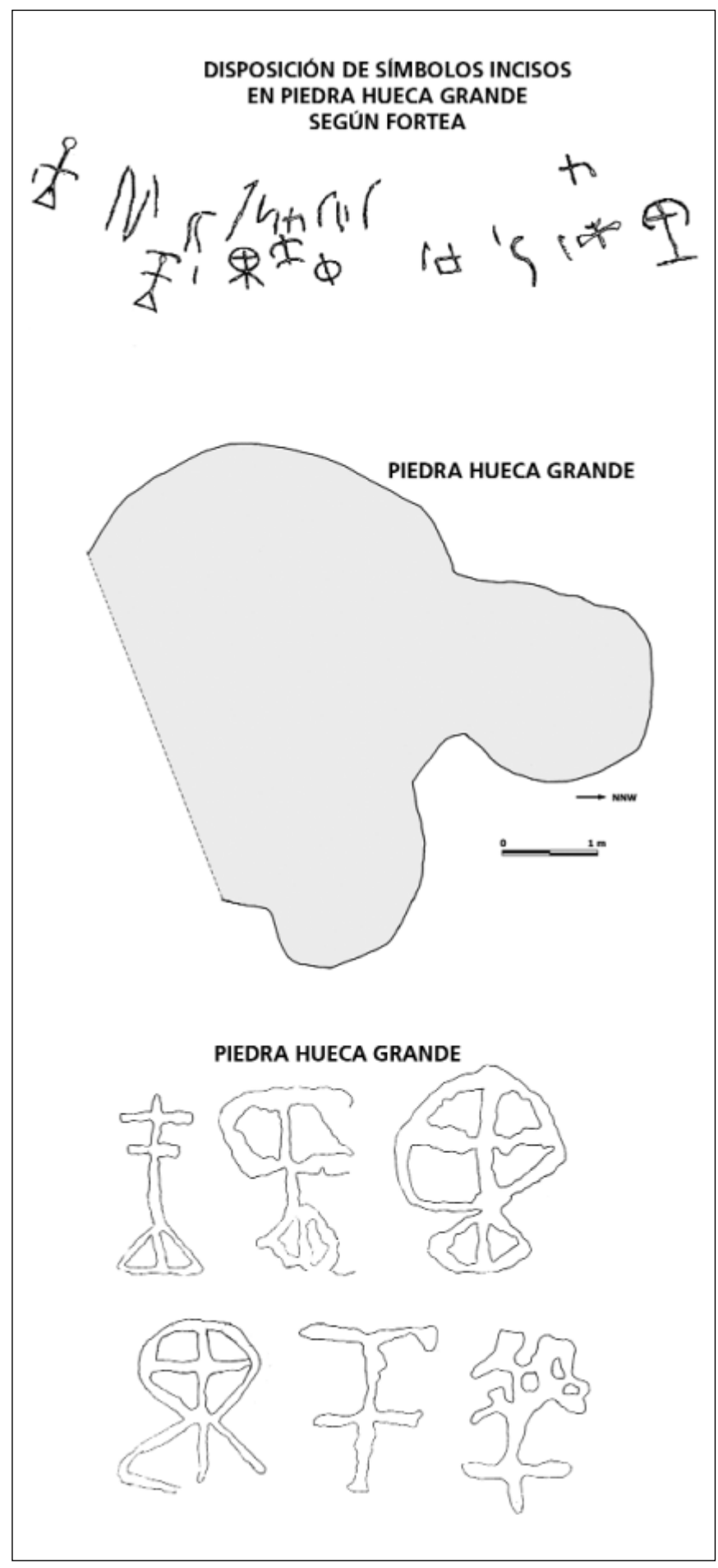

Fig. II. Piedra Hueca Grande. Planta y grabados.
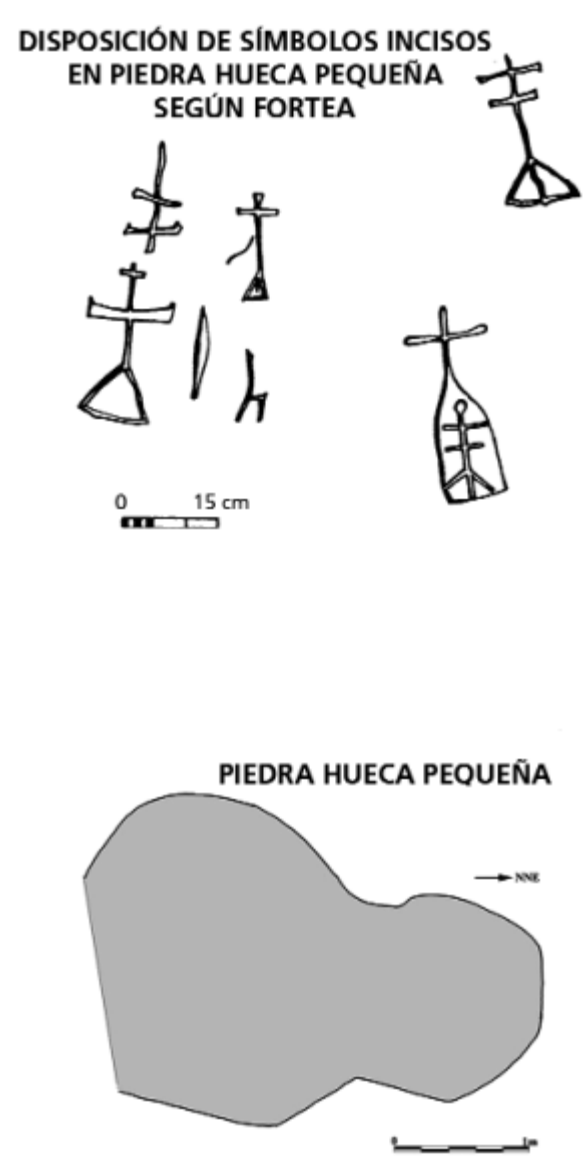

PIEDRA HUECA PEQUEÑA
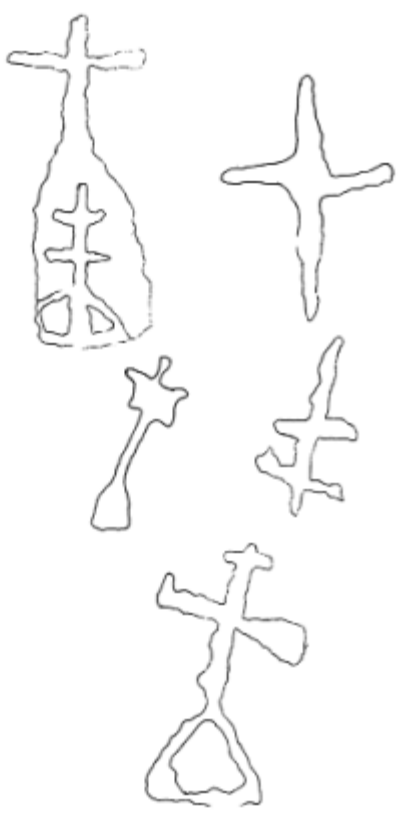

Fig. I2. Piedra Hueca Pequeña. Planta y grabados. 


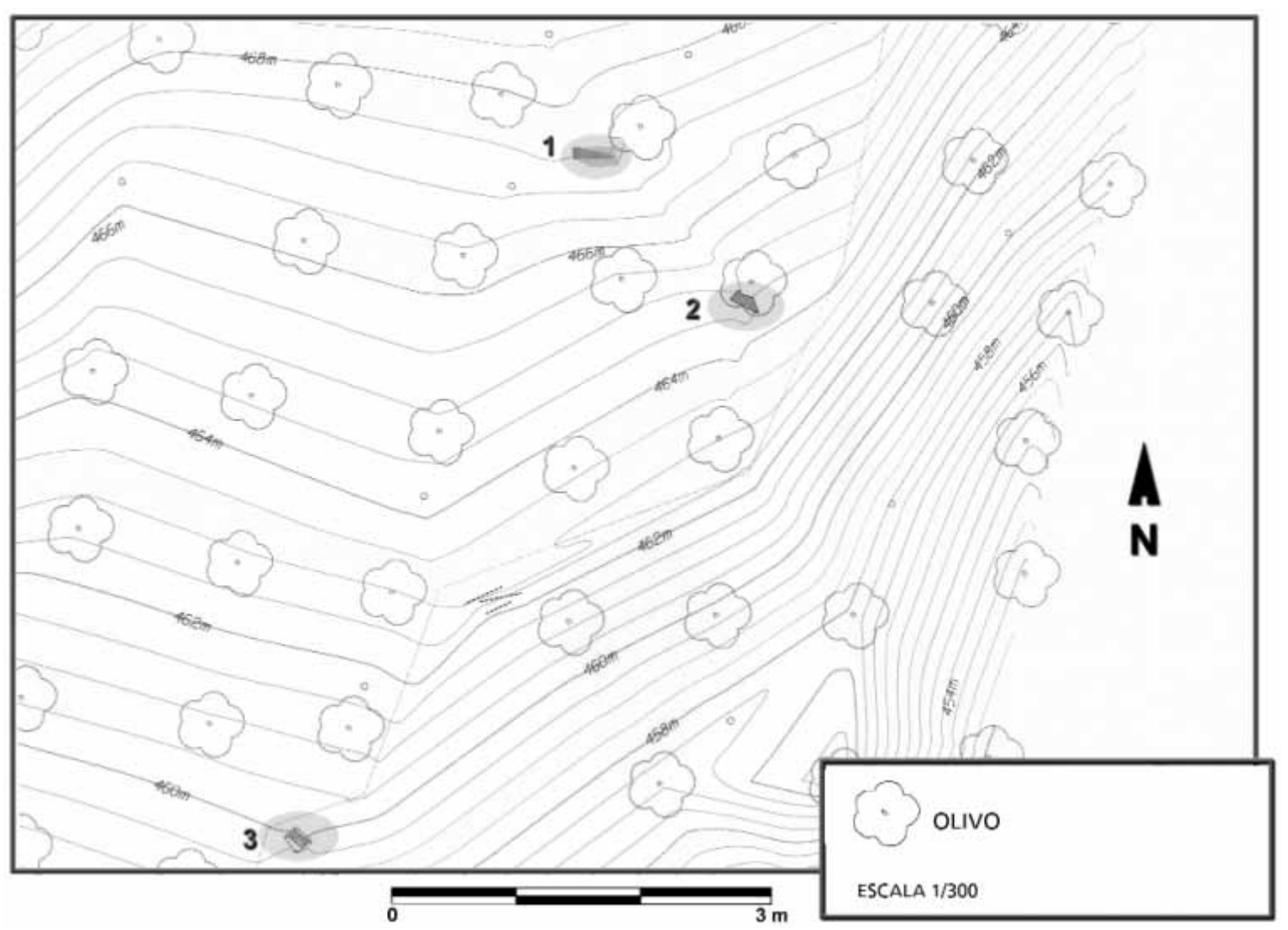

Fig. I3. Plano topográfico con indicación de los restos de la necrópolis de Casas Altas 


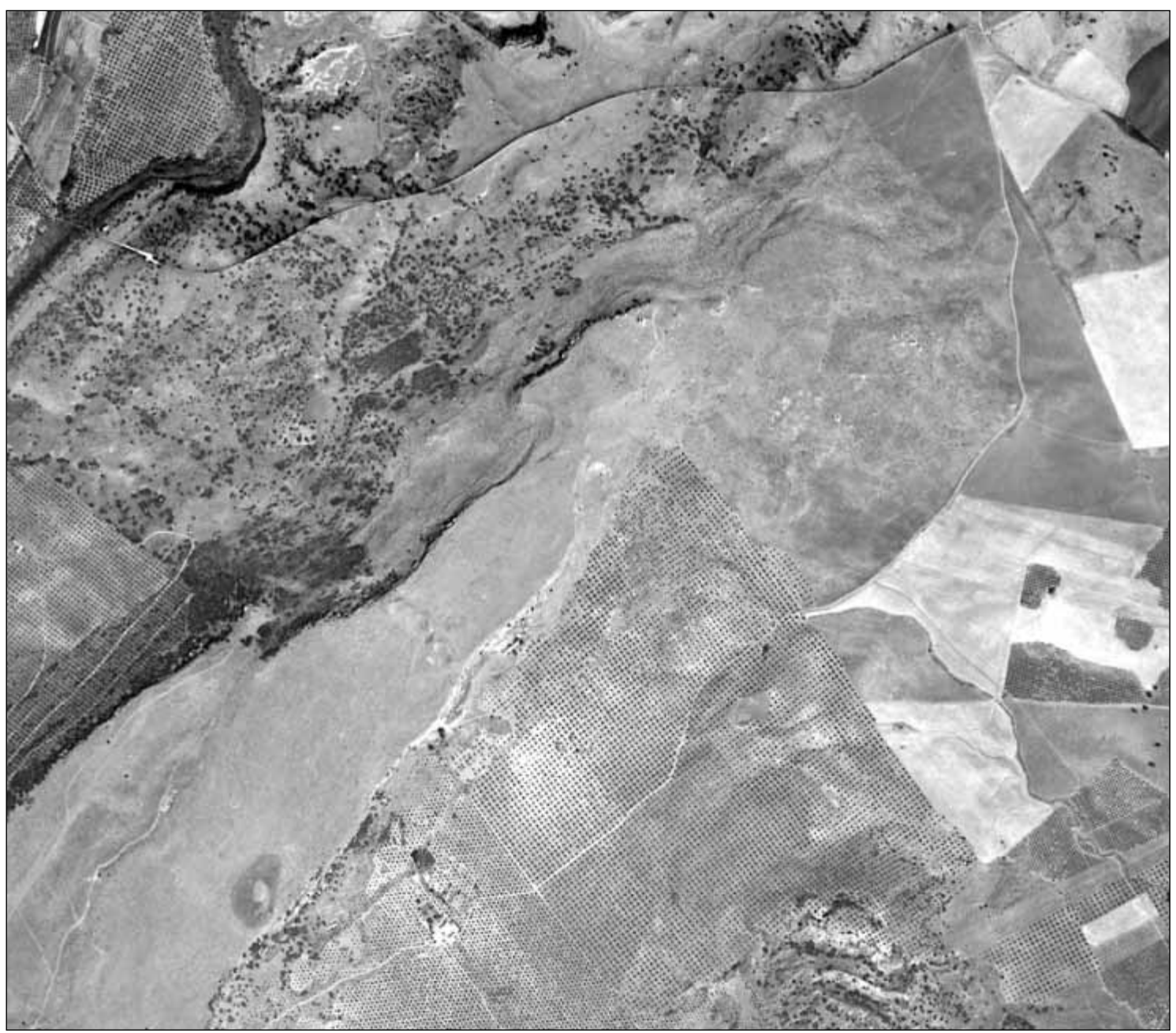

Lamina I. Vista aérea de la meseta de Giribaile.

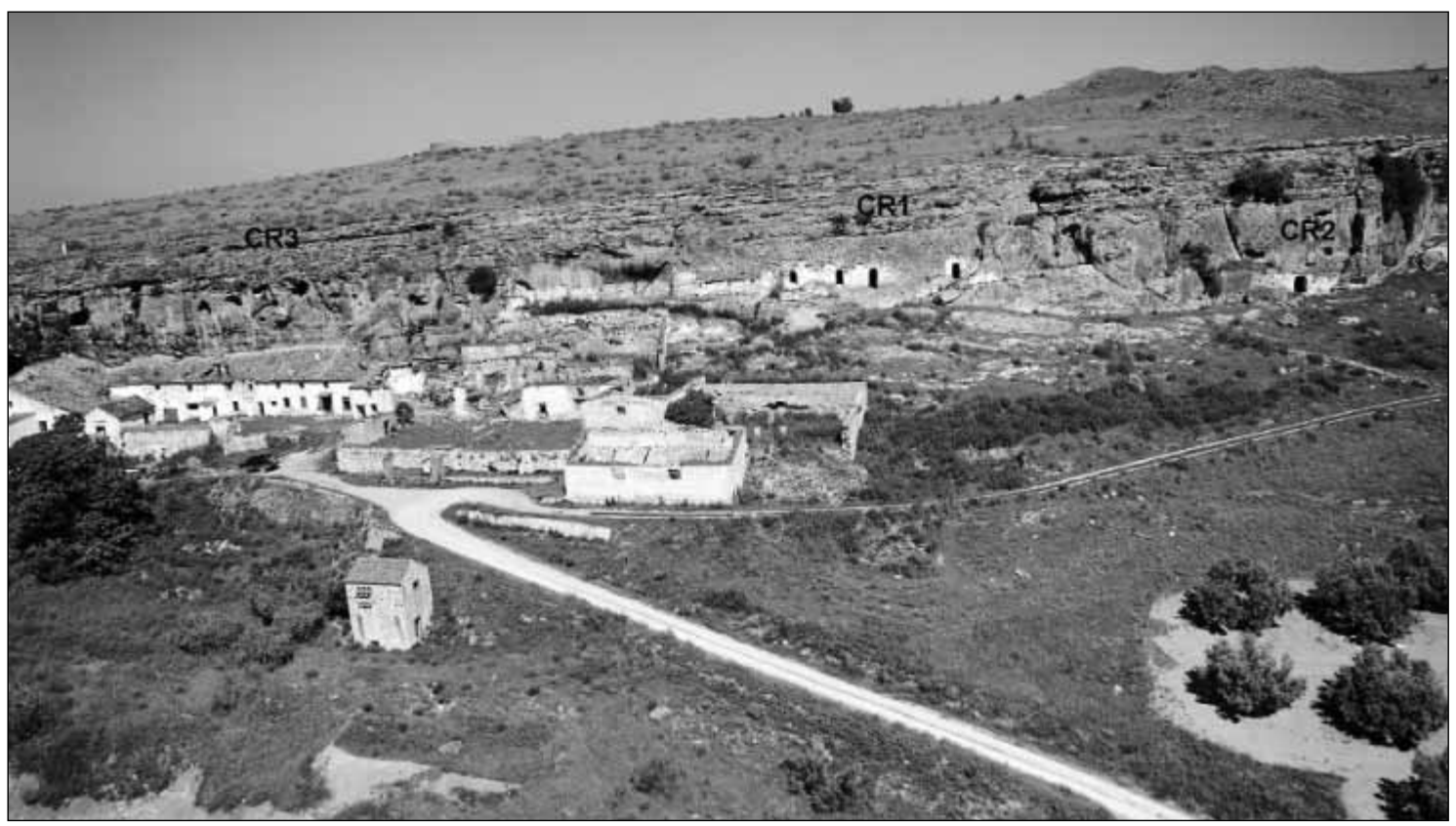

Lamina 2. Vista general del farallón con indicación de los Complejos rupestres. 


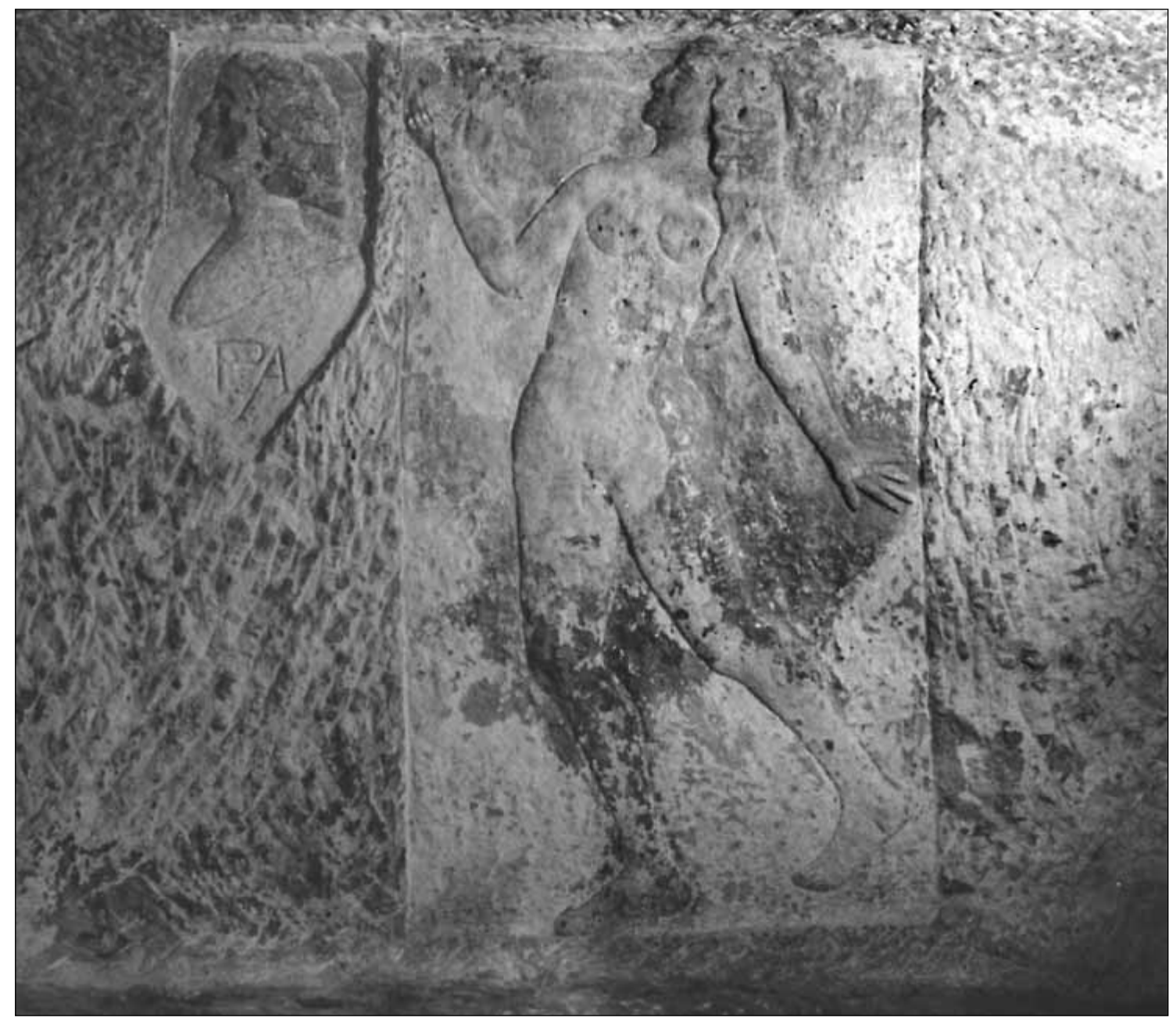

Lamina 3. Detalle de los relieves localizados en el Complejo rupestre I. 


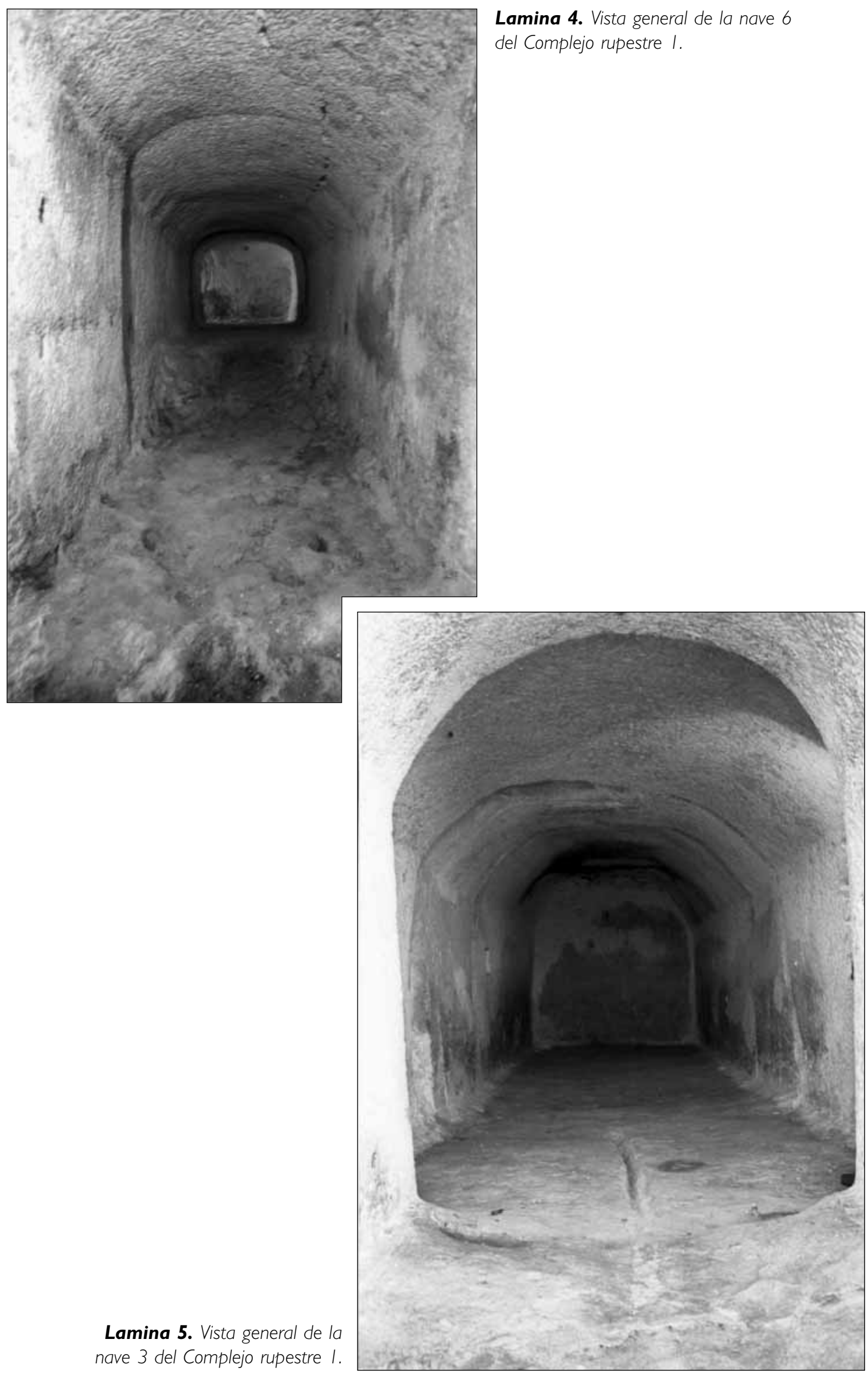




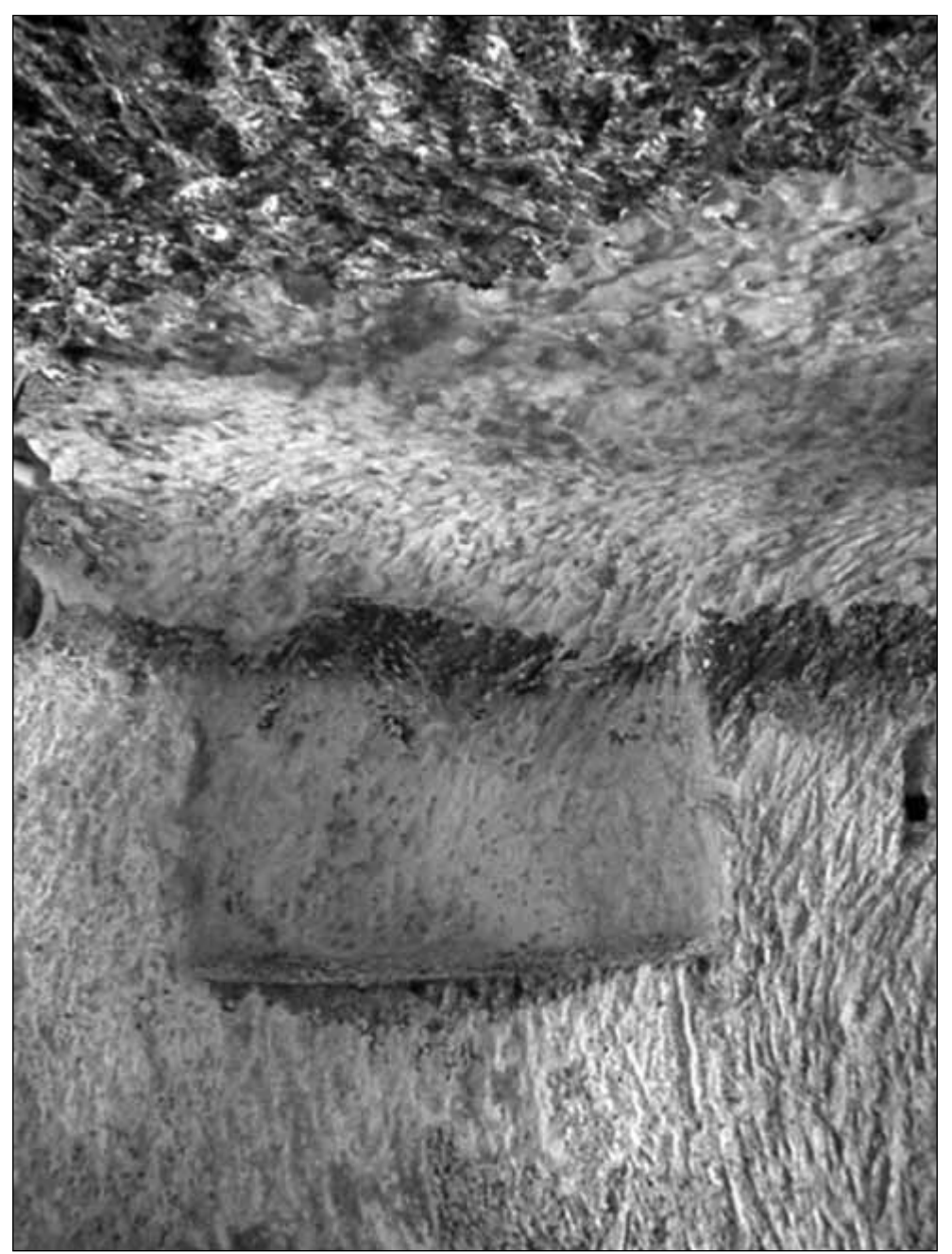

Lamina 6. Detalle de la hornacina localizada en la nave I del Complejo rupestre I.

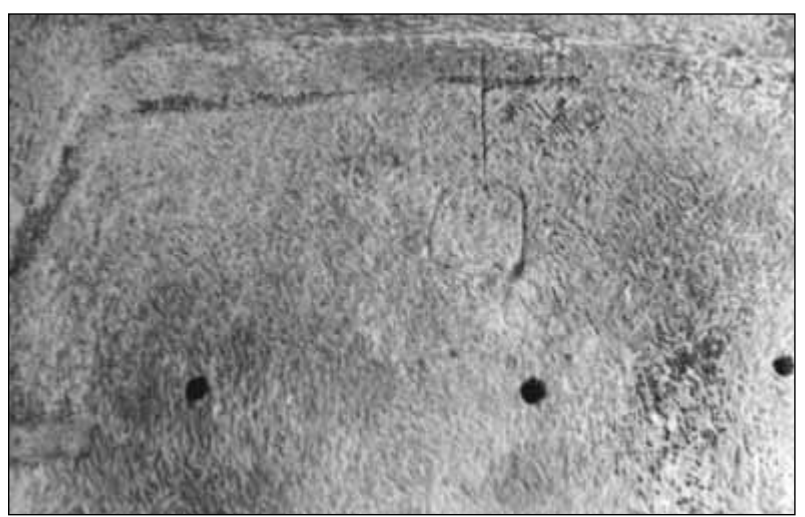

Lamina 7. Detalle de la cruz incisa documentada en el Complejo rupestre I. 


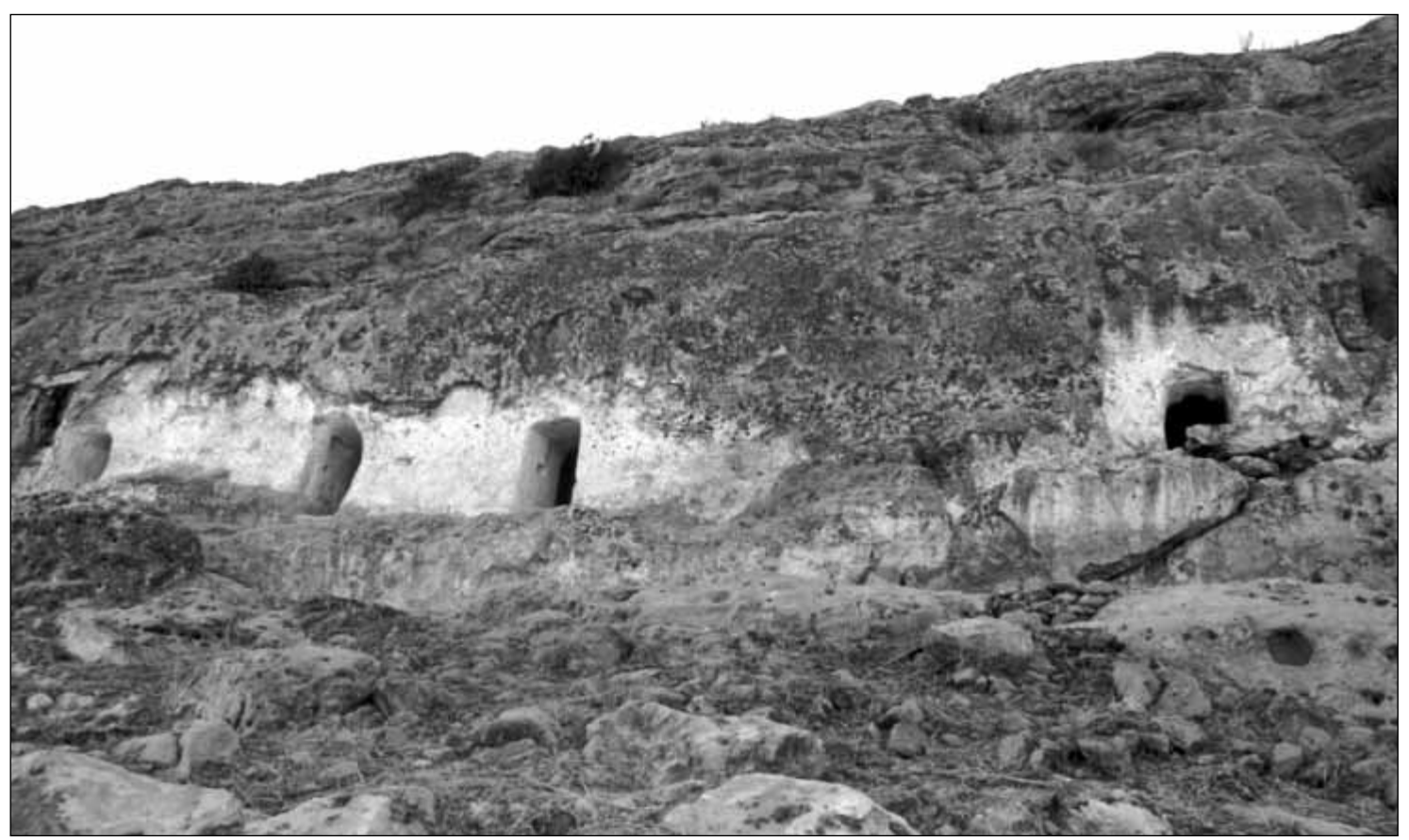

Lamina 8. Vista general de la fachada del Complejo rupestre I.

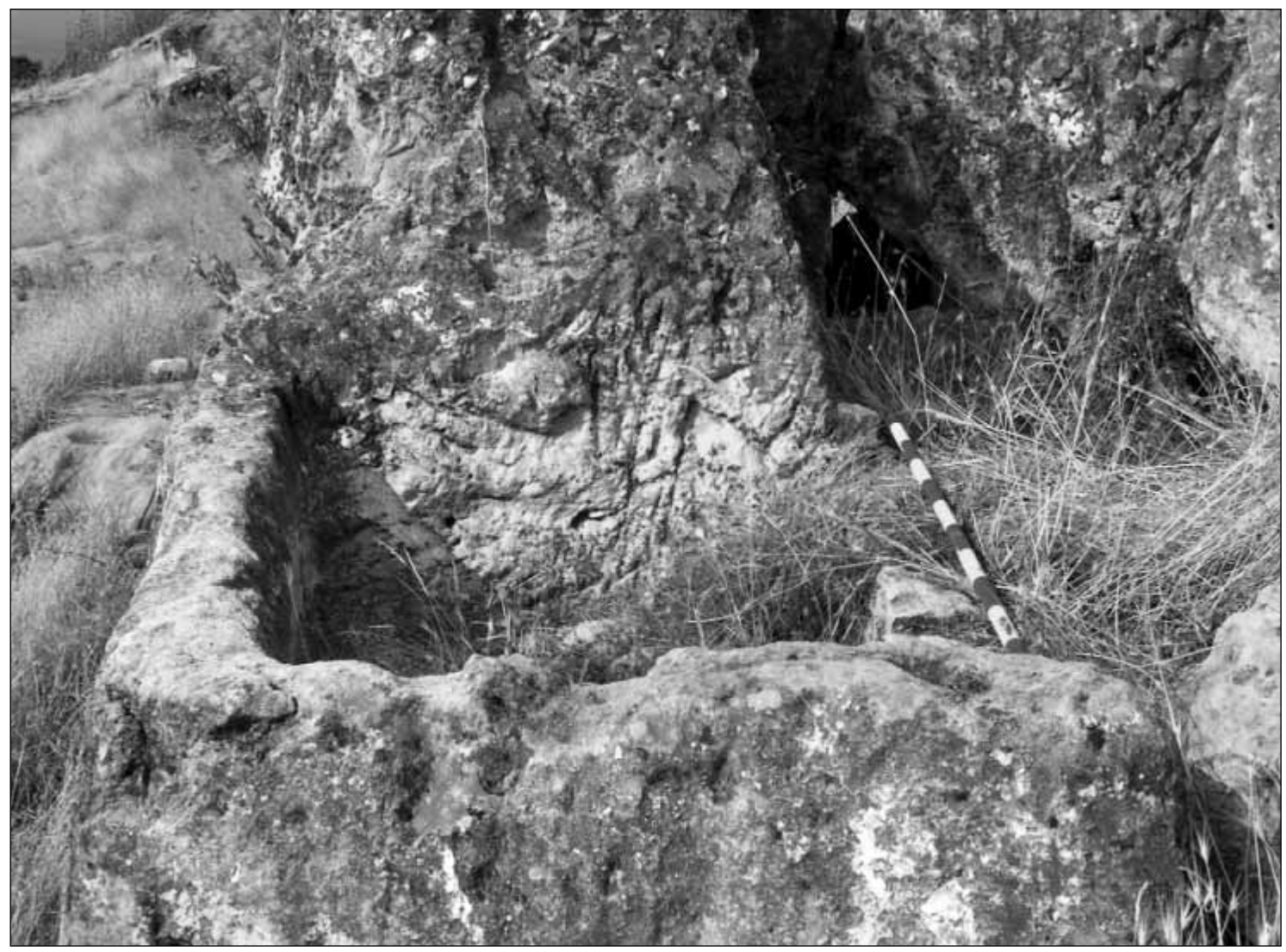

Lamina 9. Detalle de la pila localizada al exterior del Complejo rupestre I. 


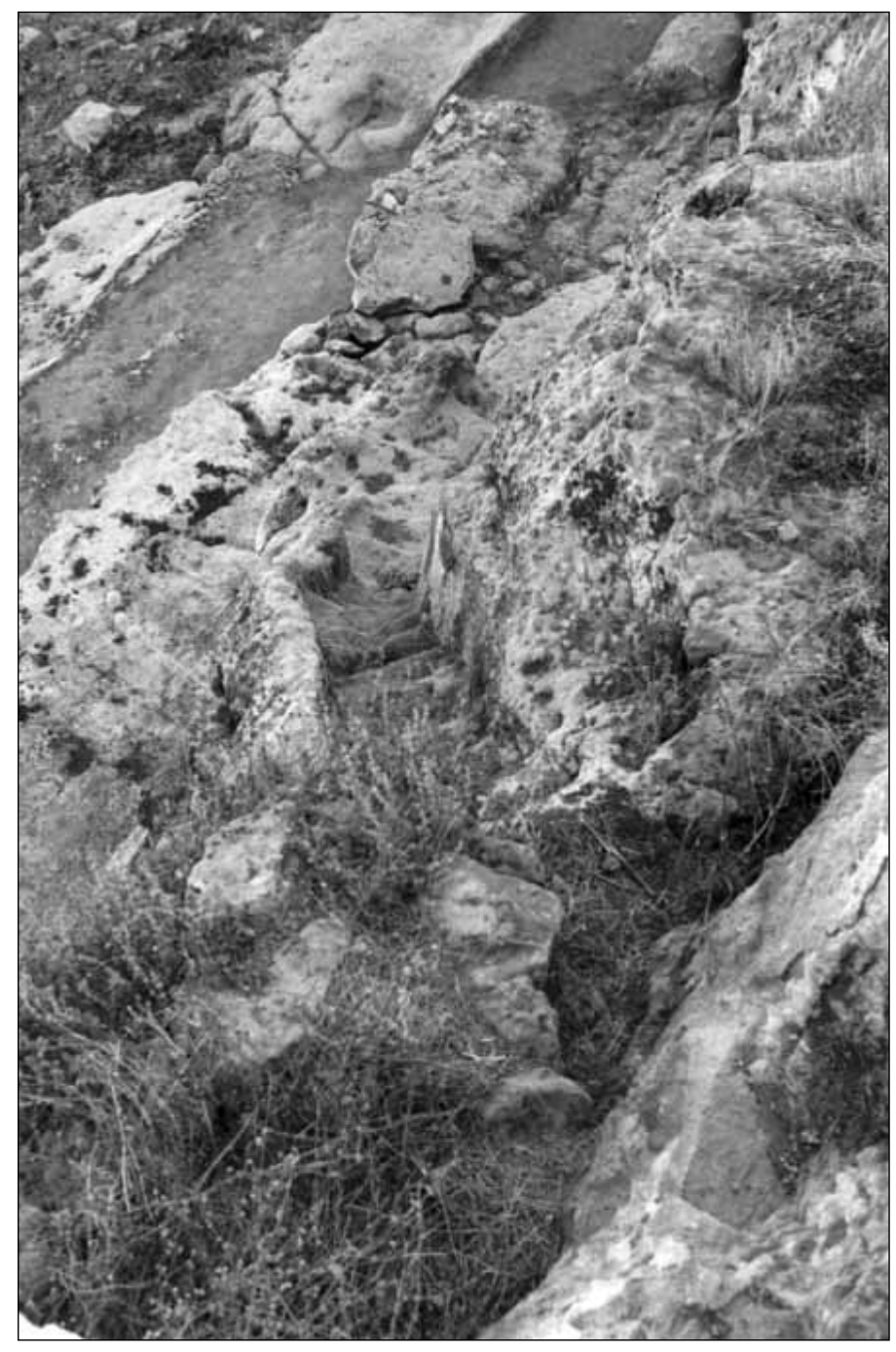

Lamina 10. Vista general de la escalera de acceso a la meseta.

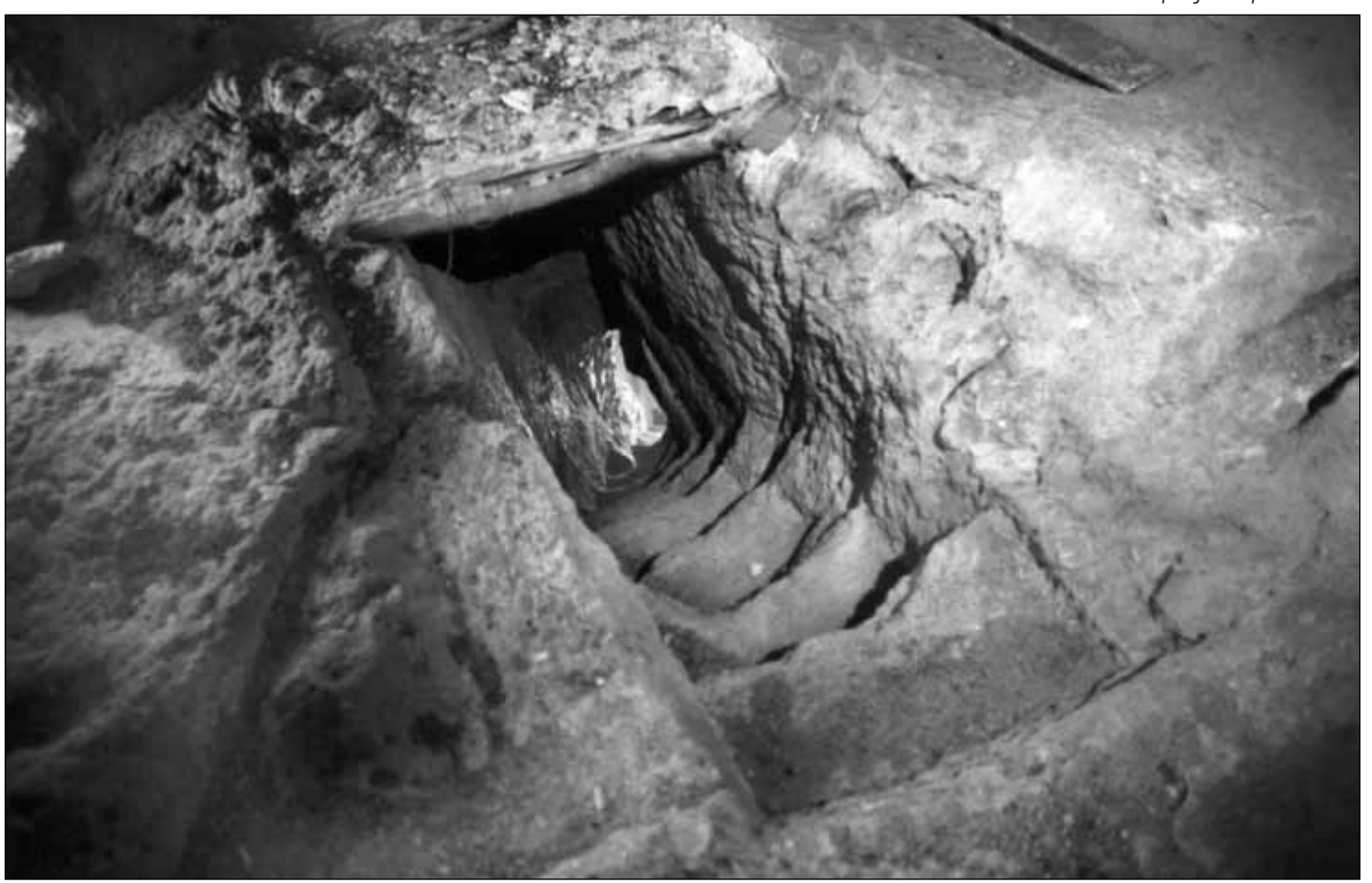


Lamina 12. Detalle de la estancia I del Complejo rupestre 3.
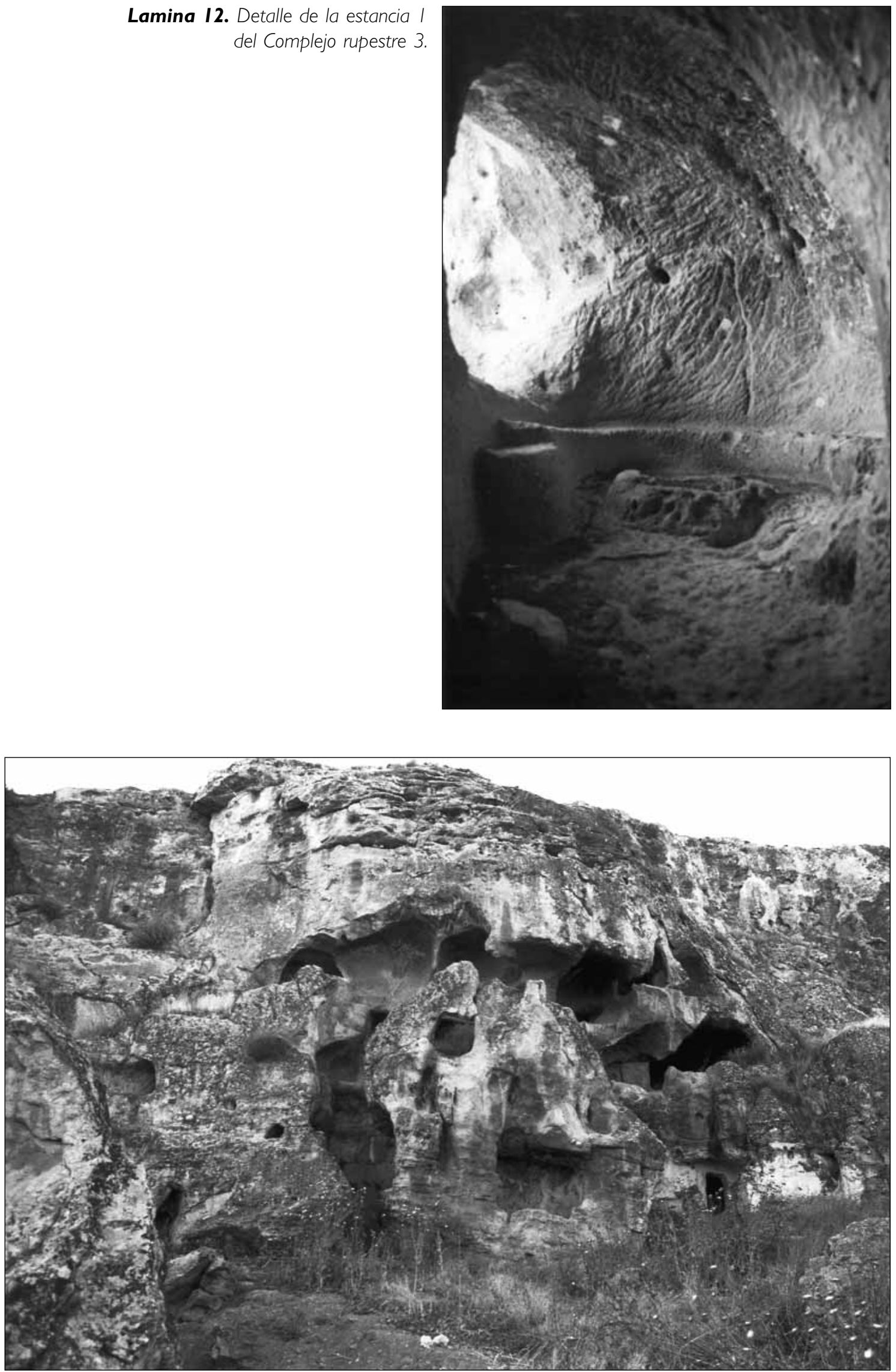

Lamina I3. Vista general del Complejo rupestre 4. 


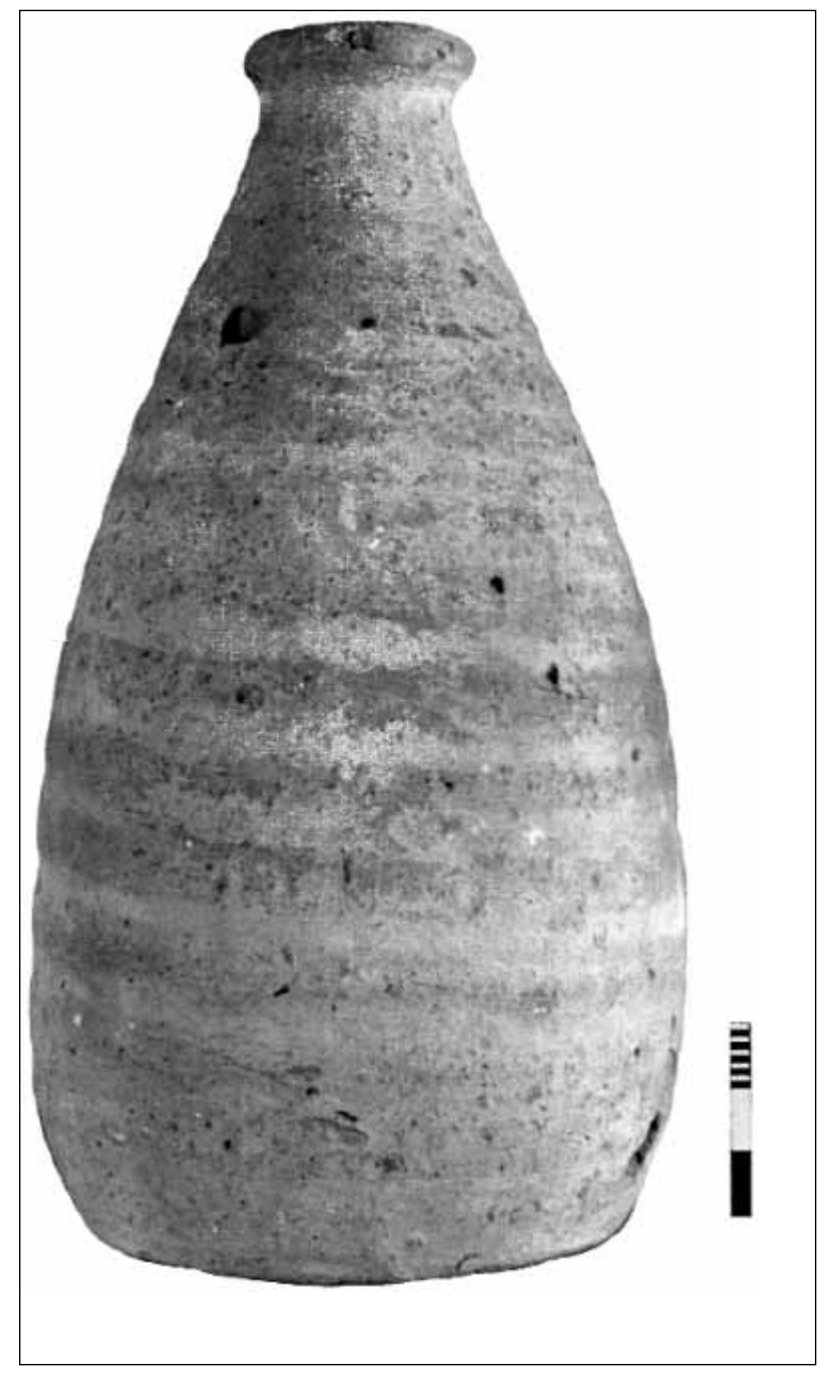

Lamina 14. Detalle de la vasija

de barro de la Colección Góngora.

Lamina I5. Vista general del exterior de Piedra Hueca Pequeña.

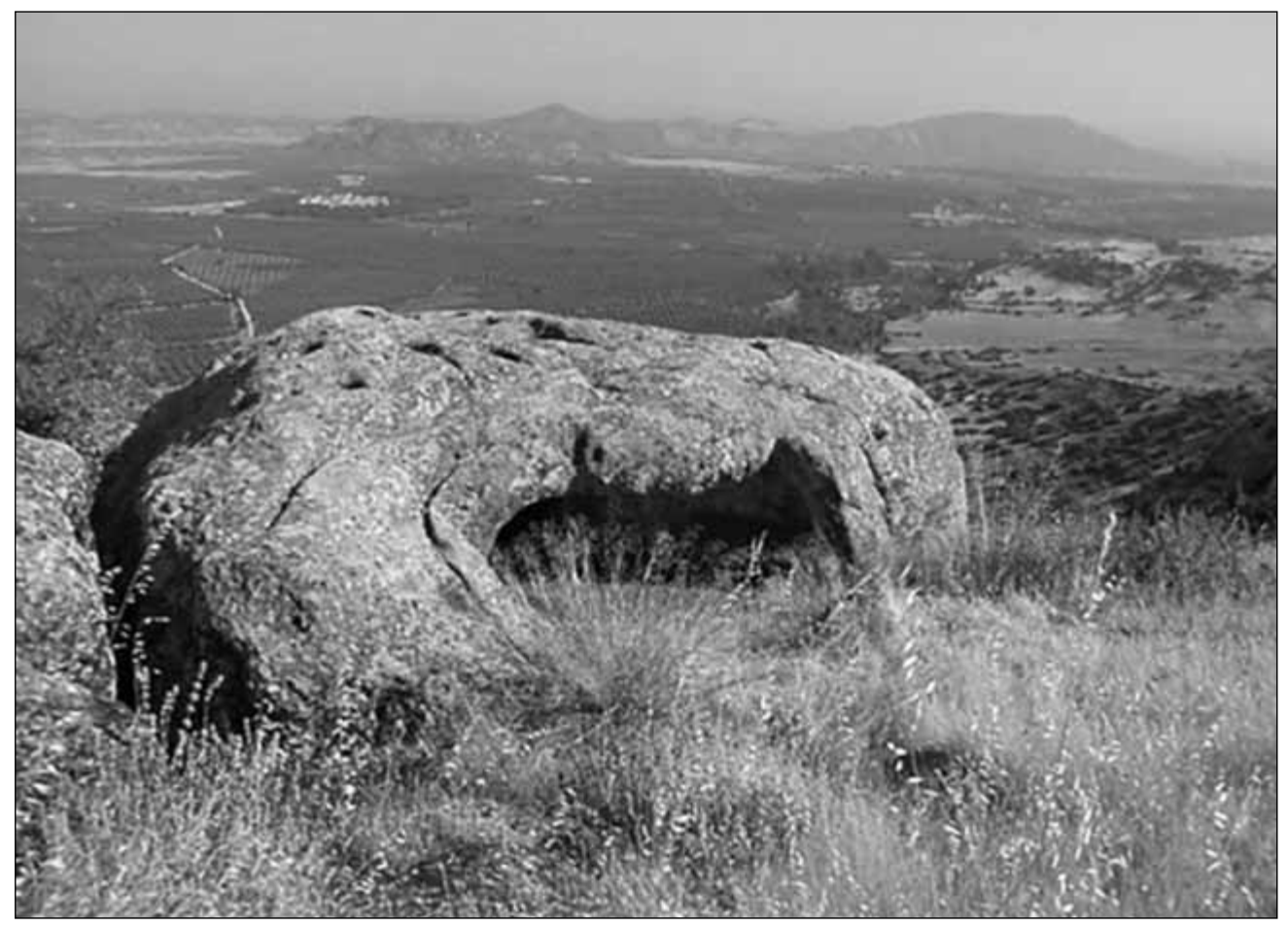




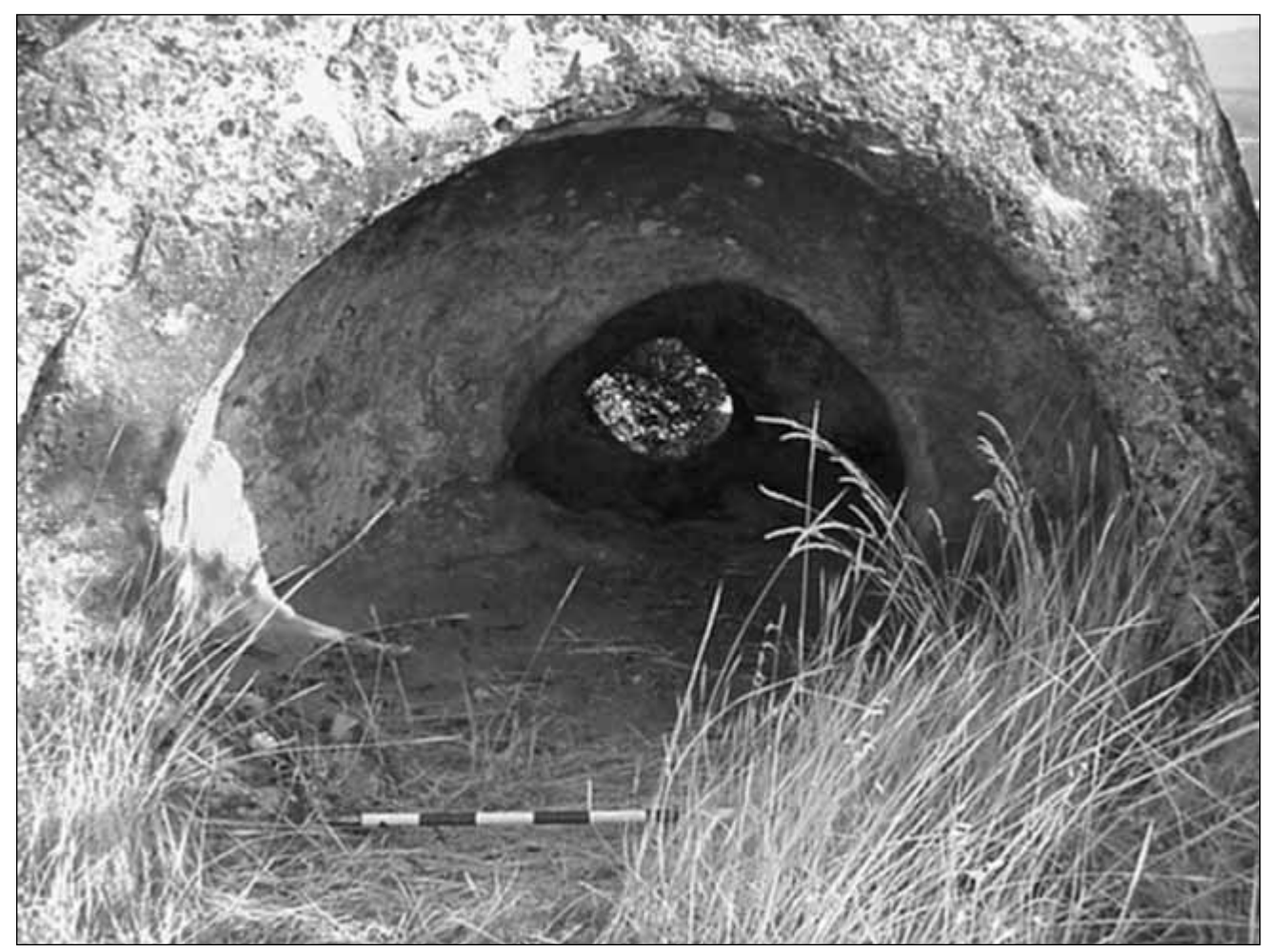

Lamina I6. Vista del interior de Piedra Hueca Grande. 